\title{
LA SITUACIÓN DE CRIMEA: LOS FUNDAMENTOS Y LOS LÍMITES DEL DERECHO INTERNACIONAL
}

\author{
CRIMEA: THE FOUNDATIONS AND LIMITS OF \\ INTERNATIONAL LAW
}

\author{
Francisca Aguayo Armijo*
}

\begin{abstract}
RESUMEN: La secesión de Crimea y su anexión a Rusia permiten recordar tanto los principios fundamentales del derecho internacional contemporáneo como los límites de su aplicación efectiva en la sociedad internacional. Efectivamente, el carácter ilícito de la situación, derivado de la intervención rusa en Ucrania, se ve confrontado al bloqueo del sistema de seguridad colectiva de las Naciones Unidas, reduciendo la reacción internacional a la obligación de no reconocer y a la eventual adopción de medidas de retorsión. El carácter limitado de la respuesta jurídica invita a reflexionar sobre la relación entre el derecho y la política en la escena internacional.
\end{abstract}

Palabras clave: Crimea, secesión, principios fundamentales del derecho internacional, obligación de no reconocer, sistema de seguridad colectiva de la ONU.

ABSTRACT: The secession of Crimea and its annexation to Russia recalls both the fundamental principles of contemporary international law and the limitations of their effective application in the international society. Indeed, the unlawfulness of the situation, which results from the Russian intervention in Ukraine, faces the deadlock of the Security Council. The international reaction is therefore restricted to the duty of non-recognition and the eventual use of retorsion. This limitation provides an opportunity to reflect on the connection between law and politics on the international stage.

Key words: Crimea, secession, fundamental principles of international law, duty of non-recognition, UN collective security system.

\section{INTRODUCCIÓN}

El referéndum de independencia en la región ucraniana de Crimea y su integración consecuente en marzo de 2014 a la Federación de Rusia han suscitado fuertes reacciones en la escena internacional. Varios son los Estados que han condenado la violación tanto de la soberanía y de la integridad territorial de Ucrania como de la prohibición del uso de la fuerza armada en derecho internacional. Las discusiones que se han desarrollado en el Consejo de Seguridad de la Organización de las Naciones Unidas (ONU) -cuya acción se encuentra bloqueada por el veto ruso- han puesto así en evidencia la oposición entre esta

\footnotetext{
* Licenciada en Derecho, mención en Derecho Internacional y Europeo, y Máster en Derecho Internacional y Organizaciones Internacionales, Universidad París 1 Panthéon-Sorbonne. Candidata a Doctor en Derecho Internacional Público y Asistente Doctoral en Relaciones Internacionales e Introducción al Derecho Internacional Público, Derecho Internacional Económico y Metodología Jurídica, Universidad París 1 Panthéon-Sorbonne. Domicilio postal: 11 Bis rue Ernest Renan, Issy-Ies-Moulineaux, Francia. Correo electrónico: aguayo.francisca@gmail.com. Todas las traducciones son de la autora.
} 
reacción generalizada y la argumentación elaborada por Rusia, que tiende a defender la integración de Crimea sobre la base del derecho de los pueblos a la autodeterminación y de la conexión histórica de su país con esta región. Frente a estas posturas opuestas, este artículo pretenderá demostrar la ilicitud de la anexión de Crimea a la Federación Rusa, poniendo simultáneamente en evidencia los límites jurídicos a los cuales se confronta la reacción de la comunidad internacional ante este hecho ilícito.

Tras una contextualización histórica, cuya presentación será el objeto de la segunda parte del trabajo, se demostrará en una tercera parte que la anexión de Crimea a la Federación rusa viola los principios fundamentales del derecho internacional público, pues es el resultado de la injerencia de Rusia en los asuntos internos de Ucrania y de la violación de su soberanía e integridad territorial por medio del uso de la fuerza. Sin embargo, pese a la ilicitud de la anexión de Crimea, la cuarta parte del trabajo pondrá en evidencia los límites substanciales e institucionales de la reacción frente al hecho ilícito en la sociedad internacional. Esta paradoja abre ciertas perspectivas de reflexión no solo sobre el rol de la política en la aplicación efectiva del derecho internacional, sino también sobre la necesidad y la pertinencia de reformas destinadas a apaciguar esta dependencia institucionalizada en cierta medida en el sistema de seguridad colectiva de las Naciones Unidas, cuyo análisis será el objeto de las consideraciones finales.

\section{CONTEXTO HISTÓRICO}

Como es habitual en el orden jurídico internacional, la comprensión de la situación en Crimea requiere una perspectiva histórica que sirve de contexto para los eventos recientes. Efectivamente, tras la formación de la Unión de Repúblicas Socialistas Soviéticas (URSS) en 1922, Crimea fue integrada como una república autónoma: la República Socialista Soviética Autónoma de Crimea. Su estatuto fue modificado al final de la Segunda Guerra Mundial, constituyendo una división administrativa dentro de la República Socialista Federativa Soviética de Rusia, quien la cedió, en 1954, a la República Socialista Soviética de Ucrania. Cuando comenzó el proceso de dislocación de la URSS, la población de Crimea intentó, sin éxito, restablecer la República Socialista Soviética Autónoma de Crimea. Pese a todo, sus reivindicaciones le permitieron obtener un estatuto autónomo dentro del Estado ucraniano, siendo primero designada como República de Crimea y a partir de 1995, tras una serie de acciones políticas de la parte de las autoridades de Crimea por independizarse, como República Autónoma de Crimea.

El caso de Crimea ilustra así la agitación que ha afectado a la vida política de Ucrania desde su independencia, por la existencia tanto de movimientos locales como nacionales marcados por la división que ha provocado la cercanía o distancia con el gobierno ruso -situación compartida con otros Estados postsoviéticos-. Así, las elecciones presidenciales de 2004, que dieron por ganador al político pro ruso Viktor Yanukovych, fueron ampliamente cuestionadas por la población e iniciaron la llamada "revolución naranja". Las manifestaciones lograron la impugnación de la elección por la Corte Suprema y la organización de nuevas elecciones que dieron por ganador al político de oposición Viktor Yushchenko, cuyo programa promovía el acercamiento hacia la Unión Europea. Su gobierno, que duró 
de 2005 hasta 2010, se vio sumergido en diversas crisis políticas que terminaron con la victoria del sector pro ruso en el Parlamento y la cohabitación desde el año 2007 con Viktor Yanukovych como primer ministro.

Durante este periodo, la política internacional de la zona postsoviética no fue menos tormentosa, reflejando de manera importante las oposiciones internas entre los sectores pro ruso y pro Unión Europea. En 2004, adhirieron a la Unión Europea y a la Organización del Tratado del Atlántico Norte (OTAN) tres Estados postsoviéticos: Estonia, Letonia y Lituania. Dentro de este contexto y frente al fracaso de las estructuras internacionales establecidas para conservar los lazos entre los Estados postsoviéticos ${ }^{1}$, Vladimir Putin lanzó la idea de crear una nueva organización internacional. Así nació en el año 2007 la Unión Aduanera formada por Rusia, Kazajistán y Bielorrusia -transformada a partir del primero de enero de 2015 en Unión Euroasiática-, que comenzó a funcionar de manera efectiva en $2010^{2}$. La intención era extender la organización a otros países postsoviéticos, dentro de los cuales Ucrania era un factor clave no solo desde una perspectiva económica, sino también política en razón de la influencia creciente de la Unión Europea en la región. Por lo mismo, de manera paralela a la instauración progresiva de la Unión Euroasiática, Rusia intentó ejercer una influencia política y económica en los países vecinos para evitar su acercamiento a la Unión Europea, lo que en el caso de Ucrania se vio principalmente reflejado en la adopción de medidas económicas favorables relativas al gas.

Sin embargo, la influencia rusa fue insuficiente para detener las negociaciones entre Ucrania y la Unión Europea, situación que se repitió en varios Estados postsoviéticos. En el año 2009, Armenia, Azerbaiyán, Bielorrusia, Georgia, Moldavia y Ucrania concluyeron el acuerdo de "Asociación Oriental" con la Unión Europea, que se revelaría más tarde como el factor detonador de la crisis actual en Crimea y en otras regiones ucranianas. El convenio, destinado a acelerar la asociación política y la integración económica con los países signatarios, permitió la entrega de 300 millones de euros de ayuda financiera por parte de la Unión Europea a Ucrania y preveía, en una fase posterior, la conclusión de un Acuerdo de Asociación entre cada país signatario y la Unión.

En este contexto político se desarrollaron en 2010 las elecciones presidenciales ucranianas que dieron por ganador a Viktor Yanukovych, reabriendo el debate sobre la posición de Ucrania con respecto a Rusia y a la Unión Europea. Frente al avance del Acuerdo de Asociación con la Unión, Rusia insistió en la adhesión de Ucrania a la Unión Aduanera, amenazando al país con medidas restrictivas a las importaciones, que fueron efectivamente

\footnotetext{
1 Véase Dreyfus (2013) pp. 8-9. El autor analiza los resultados de la Comunidad de Estados Independientes creada en 1991, la Comunidad Económica Euroasiática creada en 2000 y la Organización del Tratado de Seguridad Colectiva creada en 2004. Ucrania no es, sin embargo, miembro de ninguna de estas organizaciones, aun cuando goza, en algunas, de cierta participación como observador.

2 Cabe destacar que la Presidenta chilena Michelle Bachelet expresó durante la cumbre del Foro de Cooperación Económica Asia-Pacífico (APEC) de Pekín en noviembre de 2014 la voluntad de concluir un acuerdo de libre comercio con la Unión Aduanera. Véase, por ejemplo, EMOL, "Putin constata un "diálogo intenso político" entre Rusia y Chile en materia económica”, 9 noviembre 2014, [fecha consulta: 17 de febrero 2015]. Disponible en: <http://www.emol.com/noticias/economia/2014/11/09/689032/putin-constata-un-dialogointenso-politico-entre-rusia-y-chile.html $>$.
} 
adoptadas a partir de 2013 basándose oficialmente en la existencia de motivos sanitarios ${ }^{3}$. En noviembre del mismo año, Viktor Yanukovych renunció a la conclusión del Acuerdo de Asociación entre Ucrania y la Unión Europea, provocando una ola de manifestaciones pro Unión Europea en el país, mientras que un acuerdo estratégico fue firmado en diciembre de 2013 con Rusia. Las manifestaciones se intensificaron, así como también la represión por parte del gobierno, provocando, a principios de 2014, decenas de heridos y fallecidos.

El 22 de febrero de 2014 el Parlamento destituyó de facto a Viktor Yanukovych -quien huyó de Kiev- y nombró al día siguiente a un Presidente interino en la espera de nuevas elecciones en mayo del mismo año. Declarando ilegítimo el nuevo gobierno ucraniano, el gobierno ruso posicionó sus tropas en la frontera con Ucrania, mientras que las nuevas autoridades ucranianas, buscando atenuar los lazos con Rusia, abolieron la reforma realizada por Yanukovych, que había instaurado el ruso como segundo idioma oficial en ciertas regiones del país. Estas acciones crearon un clima aún más tenso en las regiones ruso-parlantes, en primer lugar, en Crimea, donde estalló una verdadera lucha armada entre los manifestantes pro y antirrusos, los primeros logrando imponerse en los edificios públicos donde izaron la bandera rusa. El Parlamento de Crimea decidió organizar un referéndum sobre la independencia de Crimea en mayo de 2014, para que este se realizara de manera paralela a las elecciones presidenciales en Ucrania.

El primero de marzo de 2014, el Consejo de la Federación de Rusia autorizó al gobierno a desplegar la armada rusa en el territorio de Ucrania, al mismo tiempo que las autoridades de Crimea pidieron ayuda militar a Rusia. El 11 de marzo de 2014 el Parlamento de Crimea declaró la independencia de la República Autónoma, adelantando el referéndum al 16 de marzo para obtener la aprobación de la población. Esta se pronunciaría ya no solo sobre la independencia de Crimea, sino también sobre su integración a Rusia, que ya había aceptado la solicitud previa de las autoridades locales. Aun cuando los decretos adoptados por el Parlamento de Crimea fueron declarados contrarios a la constitución ucraniana ${ }^{4}$, el referéndum fue efectivamente realizado, arrojando un 96,77 \% de votos favorables a la acción separatista 5 . Los resultados dieron lugar a la conclusión de un tratado de integración de Crimea a la Federación de Rusia, firmado por las dos entidades el 18 de marzo del $2014^{6}$.

Frente a estos actos, se desencadenaron una serie de reacciones de diferentes Estados y organizaciones internacionales para denunciar el carácter ilícito del referéndum y de la integración a Rusia -calificada de "anexión"-, adoptando sanciones contra el Estado ruso.

\footnotetext{
3 Véase, por ejemplo, NY Times, "Chocolate Factory. Trade War Victim", 29 octubre 2013 [fecha consulta: 10 de febrero 2015]. Disponible en: <http://www.nytimes.com/2013/10/30/business/international/ukrainianchocolates-caught-in-trade-war-between-europe-and-russia.html?pagewanted=all\&_r $=0>$.

4 Tribunal Constitucional de UCrania (2014) No. 02-rp/2014.

5 El referéndum fue igualmente declarado inconstitucional por el Tribunal Constitucional de Ucrania. TRIBUnal Constitucional de UCRAnia (2014) No. 03-rp/2014.

${ }^{6}$ El tratado fue considerado conforme a la constitución rusa por el Tribunal Constitucional ruso, que no se pronunció sobre las circunstancias que provocaron su conclusión ni sobre las decisiones previas del Tribunal Constitucional ucraniano (Tribunal Constitucional de Rusia, 19 de marzo del 2014, decisión N 6-П). El Tribunal consideró en su decisión que, en conformidad con el derecho internacional y el derecho ruso, el tratado podía aplicarse de manera provisoria por lo que a partir de la conclusión del tratado Crimea se había transformado en parte integrante de la Federación rusa.
} 
Aun así, desde el 21 de marzo del 2014, la región de Crimea ha sido considerada por Rusia como parte integrante de su territorio, motivando incluso una reforma de la constitución ${ }^{7}$. Por su parte, Ucrania, que concluyó el mismo día el Acuerdo de Asociación en los aspectos políticos con la Unión Europea, no ha cesado de denunciar esta situación que ha calificado de "ocupación" Porochenko, quien, ejerciendo el cargo tras las elecciones de mayo de 2014, prosiguió el acercamiento hacia la Unión Europea a través de la conclusión, un mes después, del Acuerdo de Asociación en los aspectos económicos.

Paralelamente, las reivindicaciones separatistas se agudizaron en el este de Ucrania, principalmente en las regiones de Donetsk y Lugansk donde se realizaron el 11 de mayo de 2014 referéndums similares al de Crimea. Las declaraciones consecutivas de independencia-que fueron inmediatamente denunciadas por Ucrania, mientras que Rusia solo las ha reconocido sin pronunciarse sobre las solicitudes de integración a la Federación- intensificaron los combates en los meses siguientes, pese a la firma de un acuerdo provisorio de alto al fuego en Minsk el 5 de septiembre de 2014. Meses más tarde, una nueva tentativa de negociación realizada por los presidentes de Ucrania, Rusia, Alemania y Francia permitió la conclusión, el 15 de febrero de 2015, de los “Acuerdos de Minsk 2". Respaldados posteriormente por el Consejo de Seguridad de la ONU, los Acuerdos establecen las condiciones del alto al fuego en Donetsk y Lugansk, sin pronunciarse sobre la situación de Crimea.

Así, aun cuando el conflicto separatista afecta a varias regiones de Ucrania, la situación de Crimea es particular desde el punto de vista del derecho internacional. Por un lado, no solo el referéndum de independencia sino también la integración a la Federación de Rusia ya fueron realizados y, por el otro, ningún acuerdo entre las partes en el conflicto ha sido alcanzado ni impuesto por medio del sistema de seguridad colectiva de las Naciones Unidas. Efectivamente, posiciones completamente opuestas han sido sostenidas dentro del Consejo de Seguridad de la ONU. Si bien es cierto, como ha afirmado Rusia, que la población de Crimea ha mantenido lazos estrechos con su país desde hace décadas, es necesario precisar que esta cercanía histórica no otorga a la población de Crimea el derecho de integrarse a Rusia con su ayuda militar. Por el contrario, la anexión de Crimea a la Federación Rusa viola los principios fundamentales del derecho internacional público.

\section{LA CONTRARIEDAD DE LA ANEXIÓN DE CRIMEA AL DERECHO INTERNACIONAL}

Si bien la ilicitud de la anexión de Crimea puede ser establecida de manera certera en el orden jurídico internacional, un primer apartado demostrará que esta conclusión no

\footnotetext{
7 El Parlamento ruso ratificó el tratado firmado entre Rusia y Crimea a través de una ley del 21 de marzo de 2014, que dio lugar, el mismo día, a la adopción de una ley federal de modificación de la constitución rusa para incluir Crimea y su capital, Sebastopol, dentro de la lista de las entidades de la Federación de Rusia establecida en el artículo 65.

8 El 15 de abril de 2014, tras la integración de Crimea a la Federación rusa, el Parlamento ucraniano adoptó una ley que califica Crimea y Sebastopol como territorios "provisoriamente ocupados" (Ley No 1207-VII, modificada por la Ley No 1237-VII, 6 mayo 2014).
} 
deriva del carácter unilateral de la declaración de independencia, sino de la intervención rusa en el conflicto, que será analizada en un segundo apartado.

\subsection{EL SILENCIO EN PRINCIPIO DEL DERECHO INTERNACIONAL SOBRE LA SECESIÓN}

Mucho se ha hablado en las últimas décadas sobre la posición del derecho internacional frente a los movimientos secesionistas. El argumento relativo al derecho de autodeterminación de los pueblos, cuyo alcance jurídico como derecho a la independencia ha sido exclusivamente establecido en el marco de la descolonización, ha sido extrapolado a otros contextos donde la autodeterminación externa no es, en realidad, preferida por el derecho internacional frente a los principios protectores del Estado. Esto no significa, sin embargo, que el derecho internacional prohíba la secesión fuera del contexto de la descolonización.

\subsubsection{La afirmación de la autodeterminación como derecho a la independencia excluisvamente en el marco de la descolonización}

El principal argumento jurídico utilizado para sostener la secesión de Crimea -la secesión entendida como una modalidad de creación de un nuevo Estado' - es el derecho de libre determinación de los pueblos, también conocido como derecho de autodeterminación. No solo la declaración de independencia de Crimea hace alusión al derecho de libre determinación y al "precedente" de Kosovo ${ }^{10}$, sino además, tras el referéndum en Crimea, el representante de Rusia ante el Consejo de Seguridad afirmó que "el pueblo de Crimea ha cumplido lo consagrado en la Carta de las Naciones Unidas y en numerosos instrumentos jurídicos internacionales: su derecho de libre determinación"11.

El derecho de autodeterminación se encuentra efectivamente proclamado en el artículo primero de la Carta de las Naciones Unidas que establece los objetivos de la Organización. Así, la ONU fue creada, entre otros fines, para "[f]omentar entre las naciones relaciones de amistad basadas en el respeto al principio de la igualdad de derechos y al de la libre determinación de los pueblos" ${ }^{12}$. Sin embargo, la introducción de esta disposición en el acto constitutivo de la ONU no significaba, en aquella época, la proclamación de un verdadero derecho ${ }^{13}$. En 1945, la noción de pueblo se entendía en el marco de un Estado y la necesidad política de recordar la libre determinación de cada pueblo tenía una relación directa con los eventos relativos a las guerras mundiales -interestatales- que habían motivado la creación sucesiva de la Sociedad de Naciones y de la ONU. La Carta de las Naciones Unidas pretendía así recordar la soberanía de todo Estado y el principio correlativo de la no intervención, sin buscar condenar, de manera alguna, la ausencia de determinación de los pueblos sometidos a una potencia extranjera ${ }^{14}$. Basta recordar, para esto, la reglamentación

\footnotetext{
9 Véase Salmon (2001) pp. 1021-1022.

10 Véase Boeglin (2014).

11 CSNU, S/PV. 7144, p. 8.

12 Carta de las Naciones Unidas, art. 1, párr. 2. La expresión se repite en el artículo 55 de la Carta, relativo a la acción de la Organización en materia económica y social.

13 Véase Salmon (2001) p. 379.

14 Véase, en este sentido, Pellet (1995) pp. 255-256.
} 
de la colonización -y no su condena ni su prohibición- a través del capítulo XI de la Carta dedicado a los "territorios no autónomos".

No es sino a partir de la segunda mitad del siglo XX que la concepción del derecho de autodeterminación comienza a cambiar, con las reivindicaciones independentistas de los pueblos colonizados. En 1960, la Asamblea General de la ONU declara en su resolución $1514(\mathrm{XV})$ titulada "Declaración sobre la concesión de la independencia a los países y pueblos coloniales", que "[t]odos los pueblos tienen el derecho de libre determinación"15, precisando las modalidades para que "los pueblos dependientes puedan ejercer pacífica y libremente su derecho a la independencia completa" ${ }^{16}$. El derecho de autodeterminación se entiende así en el marco de la descolonización, beneficiando a los pueblos sometidos a una "subyugación, dominación y explotación extranjera"17. Por lo mismo, la resolución recuerda la ilicitud de todo ataque contra "la unidad nacional y la integridad territorial de un país"18.

La idea es reiterada por la Asamblea General en la resolución 2625 (XXV) de 1970, que requiere a los Estados "poner fin rápidamente al colonialismo"19 y recuerda, simultáneamente, que "[n]inguna de las disposiciones de los párrafos precedentes se entenderá en el sentido de que autoriza o fomenta cualquier acción encaminada a quebrantar o menospreciar, total o parcialmente, la integridad territorial de Estados soberanos e independientes que se conduzcan de conformidad con el principio de la igualdad de derechos y de la libre determinación de los pueblos antes descritos" ${ }^{20}$. Esta precisión es fundamental en cuanto permite entender que el derecho de autodeterminación no es sinónimo de derecho de secesión -autodeterminación externa-, pues la libre determinación de un pueblo puede ser respetada en el marco de un Estado preexistente, es decir, por medio de una autodeterminación "interna”.

No obstante, se ha observado en doctrina que el derecho de libre determinación en la resolución 2625 (XXV) está formulado en términos generales ${ }^{21}$, contrariamente a la resolución 1514 (XV) que se refiere exclusivamente al fenómeno de colonización. Efectivamente, la resolución 2625 (XXV) afirma que "todos los pueblos tienen el derecho de determinar libremente, sin injerencia externa, su condición política y de proseguir su desarrollo económico, social y cultural, y todo Estado tiene el deber de respetar este derecho de conformidad con las disposiciones de la Carta"22, a través del "establecimiento de un Estado soberano e independiente, la libre asociación o integración con un Estado independiente o la adquisición de cualquier otra condición política libremente decidida por un pueblo"23. Esta formulación general permite afirmar al profesor Pierre Michel Eisemann que no existe razón alguna para restringir el derecho de libre determinación a los pueblos colonizados ${ }^{24}$, más aún teniendo

\footnotetext{
15 AGNU, A/RES/1514 (XV), párr. 2.

16 AGNU, A/RES/1514 (XV), párr. 4.

17 AGNU, A/RES/1514 (XV), párr. 1.

18 AGNU, A/RES/1514 (XV), párr. 6.

19 AGNU, A/RES/2625 (XXV), anexo.

20 AGNU, A/RES/2625 (XXV), anexo.

21 Véase, por ejemplo, Acosta Sánchez (2014) p. 7, Eisemann (2010) p. 113.

22 AGNU, A/RES/2625 (XXV), anexo.

23 AGNU, A/RES/2625 (XXV), anexo.

24 EISEMANn (2010) p. 113.
} 
en cuenta que la Corte Internacional de Justicia (CIJ) lo ha considerado como un "principio esencial del derecho internacional contemporáneo" 25 válido erga omnes ${ }^{26}$.

Sin embargo, el análisis de la jurisprudencia de la CIJ en la materia revela una diferencia esencial en el alcance del derecho de libre determinación dentro y fuera del contexto de la descolonización. Así, en su opinión consultativa de 1971 sobre la presencia de Sudáfrica en Namibia, la Corte afirmó que "la evolución posterior del derecho internacional con respecto de los territorios no autónomos, tal y como es consagrado por la Carta de las Naciones Unidas, ha hecho de la autodeterminación un principio aplicable a todos estos territorios" ${ }^{27}$, refiriéndose exclusivamente a los "territorios no autónomos". Estos corresponden a los territorios que figuran en la lista elaborada por el Comité Especial de la Descolonización ${ }^{28}$, establecido en 1961 por la Asamblea General de la ONU para estudiar la aplicación de la resolución 1514 (XV). La lista comprende actualmente diecisiete territorios -incluyendo, por ejemplo, el Sahara Occidental y las Islas Malvinas-, dentro de los cuales no figura Crimea. Efectivamente, los territorios no autónomos -o coloniales- han sido definidos por la Asamblea General de la ONU como aquellos "separado[s] geográficamente del país que lo[s] administra y [que son] distinto[s] de este en sus aspectos étnicos o culturales"29.

La distinción sobre el alcance del derecho de autodeterminación dentro y fuera del fenómeno colonial queda aún más clara cuando se estudia la opinión consultativa de la CIJ de 2010 sobre la conformidad al derecho internacional de la declaración de independencia de Kosovo - caso que ha sido invocado como precedente por Crimea pues se trata igualmente de una secesión realizada fuera del marco de la descolonización-. En su opinión consultativa, la Corte se limitó a constatar las consecuencias jurídicas del derecho de libre determinación respecto de los territorios colonizados, evitando la cuestión del alcance del derecho fuera del fenómeno de descolonización. Según la Corte, la evolución del derecho internacional en materia de autodeterminación durante la segunda mitad del siglo XX provocó "el nacimiento de un derecho a la independencia de los pueblos de territorios no autónomos y aquéllos que estaban sometidos a la subyugación, a la dominación o a la explotación extranjera" ${ }^{30}$. Respecto de los otros casos, la Corte observó la existencia de visiones divergentes, ya sea sobre el alcance del derecho de autodeterminación o sobre el valor de la teoría de la "secesión remedio", que fue invocada para justificar la independencia de Kosovo en razón de la violación masiva de los derechos humanos del pueblo kosovar en Serbia ${ }^{31}$.

25 CIJ, Timor oriental (Portugal c. Australie) (1995) p. 102, párr. 29.

26 CIJ, Conséquences juridiques pour les États de la présence continue de l'Afrique du Sud en Namibie (Sud-Ouest africain) nonobstant la résolution 276 (1970) du Conseil de sécurité (1976) p. 31, párr. 52.

27 CIJ, Conséquences juridiques pour les États de la présence continue de l'Afrique du Sud en Namibie (Sud-Ouest africain) nonobstant la résolution 276 (1970) du Conseil de sécurité (1976) p. 31, párr. 52.

28 Su nombre oficial es "Comité Especial encargado de examinar la situación con respecto a la aplicación de la Declaración sobre la concesión de la independencia a los países y pueblos coloniales”.

29 AGNU, A/RES/1541 (XV), anexo, principio IV.

30 CIJ, Conformité au droit international de la déclaration unilatérale d'indépendance relative au Kosovo (2010) p. 436, párr. 79 .

31 CIJ, Conformité au droit international de la déclaration unilatérale d'indépendance relative au Kosovo (2010) p. 438, párr. 82 . 
La aplicación de la teoría de la "secesión remedio" al caso de Crimea ha sido, de cierta manera, sugerida implícitamente por Rusia al relacionar la validez de la independencia de Crimea con la necesidad de proteger la población local de la represión del gobierno ucraniano. En doctrina, los partidarios de la teoría se apoyan en la letra de la resolución 2625 (XV) para afirmar que la integridad territorial de los Estados solo debe ser respetada cuando estos se "conduzcan de conformidad con el principio de la igualdad de derechos y de la libre determinación de los pueblos antes descritos y estén, por tanto dotados de un gobierno que represente a la totalidad del pueblo perteneciente al territorio, sin distinción por motivo de raza, credo o color" 32 . Sin embargo, consideraciones de hecho y de derecho se oponen a la aplicación de esta teoría tanto de manera general como en el caso particular de Crimea.

Con respecto al valor jurídico de la tesis de la "secesión remedio", cabe recordar, como ya ha sido señalado, que la CIJ evitó la cuestión en su opinión consultativa de 2010 limitándose a constatar la existencia de un profundo desacuerdo entre los Estados en la materia. Esto equivale a afirmar, "en definitiva, la ausencia de suficiente práctica y de opinio iuris" ${ }^{33}$ para establecer una norma consuetudinaria, contrariamente al derecho de libre determinación -entendido como derecho a la independencia- de los pueblos colonizados ${ }^{34}$. Más aún, como afirma la profesora Hélène Ruiz-Fabri, la introducción en la resolución 2625 (XXV) de ciertas exigencias de comportamiento para los Estados respecto del derecho de autodeterminación de los pueblos no significa que a partir del momento en que un gobierno desconoce los derechos de las minorías estas encuentren un fundamento en el derecho internacional para independizarse. Según la profesora, los límites sobre la representatividad del gobierno introducidos en la resolución significan, en el mejor de los casos, que el derecho internacional abandona en cierta medida su neutralidad hacia el derecho nacional para garantizar una cierta protección a las minorías en el plano interno. La autora precisa, no obstante, que ni siquiera esta concepción del alcance del derecho de autodeterminación fuera de la descolonización se refleja completamente en el derecho internacional positivo ${ }^{35}$.

Pero incluso si es que se aceptase el valor jurídico de la teoría de la "secesión remedio”, su aplicación al caso de Crimea sería extremadamente cuestionable. Contrariamente a la situación de Kosovo, no se ha constatado en Crimea ninguna violación masiva de los derechos humanos que pudiese justificar el recurso a tal fundamento para la secesión, siendo esencial, en este sentido, distinguir el conflicto civil que se desarrolla desde 2013 de la opresión masiva de un pueblo en razón de su condición de minoría. Por lo mismo, aun cuando ciertas conductas puedan ser consideradas como atentatorias contra los derechos de la población ruso-parlante en Ucrania - particularmente la abolición del ruso como segundo idioma oficial en ciertas regiones del país-, estas medidas son claramente insuficientes para constituir violaciones graves y masivas de los derechos humanos de una minoría. Es más, como lo ha señalado Christian Marxsen, Crimea ya gozaba de un estatuto autónomo

\footnotetext{
32 AGNU, A/RES/2625 (XXV), anexo.

33 López-Jurado Romero de la Cruz (2011) p. 24.

34 Véase Christakis (2014) pp. 737-742.

35 Ruiz-Fabri (1992) pp. 158-160.
} 
dentro del Estado ucraniano, el cual, consagrado constitucionalmente, le permitía el ejercicio de la autodeterminación interna ${ }^{36}$.

Así, la secesión de Crimea no puede fundarse en el derecho de libre determinación, pues en el derecho internacional contemporáneo este es garantizado, bajo la forma de la independencia, solo para los pueblos colonizados. Sin embargo, la ausencia de un derecho a la independencia no significa que la secesión realizada fuera del contexto de la descolonización sea prohibida por el derecho internacional.

\subsubsection{La ausencia de prohibición de la secesión en derecho internacional}

Dado que el derecho de autodeterminación es establecido en el orden jurídico internacional como derecho a la independencia únicamente en el contexto de la descolonización, se podría concluir que los principios de derecho internacional protectores del territorio del Estado -soberanía, integridad territorial e intangibilidad de las fronteras- implican una prohibición de la secesión en los otros casos. Efectivamente, numerosos Estados presentaron observaciones durante el procedimiento consultativo relativo a la declaración de independencia de Kosovo $^{37}$ indicando que el principio de integridad territorial contiene una prohibición implícita de la secesión ${ }^{38}$.

La cuestión del impacto del principio de integridad territorial en la licitud de la declaración de independencia de Kosovo fue analizada por la CIJ a partir de la terminología utilizada en los principales textos que lo consagran. Así, la Corte estudió la redacción del artículo 2 párrafo 4 de la Carta de las Naciones Unidas, de la resolución 2625 (XV) de la Asamblea General -que refleja en este aspecto la costumbre internacional ${ }^{39}$ - y el acto final de la Conferencia de Helsinki que creó la Organización por la Seguridad y la Cooperación en Europa, observando que estos documentos se refieren solamente a las relaciones entre Estados. La Corte concluyó que "el alcance del principio de integridad territorial se limita entonces a la esfera de las relaciones interestatales" ${ }^{\prime 0}$. En otras palabras, una entidad que pretende independizarse, no siendo aún un Estado, no está obligado por dichos principios del derecho internacional.

Ante la ausencia de una prohibición derivada de los principios generales de derecho internacional, la CIJ analizó la existencia eventual de una norma internacional consuetudinaria prohibitiva de la secesión. No obstante, frente a las declaraciones de independencia efectuadas durante la segunda mitad del siglo XX fuera del contexto de la descolonización,

\footnotetext{
36 Véase MarXSEn (2014).

37 El artículo 66 del Estatuto de la CIJ prevé tanto la comunicación de la solicitud de opinión consultativa "a todos los Estados que tengan derecho a comparecer ante la Corte" (párr. 1) como la notificación a dichos Estados de la posibilidad de presentar exposiciones escritas u orales (párr. 2). Sobre esta base, cuarenta y tres países presentaron observaciones escritas u orales, entre los cuales figuraban cuatro Estados latinoamericanos: Argentina, Bolivia, Brasil y Venezuela.

${ }_{38} \mathrm{CIJ}$, Conformité au droit international de la déclaration unilatérale d'indépendance relative au Kosovo (2010) p. 437, párr. 80.

39 CIJ, Activités militaires et paramilitaires au Nicaragua et contre celui-ci (Nicaragua c. États-Unis d'Amérique), fond (1986) pp. 101-103, párr. 191-193.

$40 \mathrm{CIJ}$, Conformité au droit international de la déclaration unilatérale d'indépendance relative au Kosovo (2010) p. 437, párr. 80.
} 
la Corte observó que "la práctica de los Estados no parece indicar que la declaración de independencia haya sido considerada como una violación del derecho internacional. Por el contrario, la práctica dentro de este periodo muestra claramente que el derecho internacional no prohibía de manera alguna las declaraciones de independencia” ${ }^{31}$.

Cabe destacar que la conclusión no es formulada en términos positivos, sino negativos. La Corte se limitó a constatar que "el derecho internacional general no contiene ninguna prohibición de las declaraciones de independencia” ${ }^{2}$, luego de haber afirmado, claramente, y en términos positivos, que en el caso de la descolonización el derecho internacional apoya el nacimiento de nuevos Estados. En efecto, la opinión consultativa de 2010 de la Corte "did not answer the question whether Kosovo had a right to secession under international law; it did not address the question whether there is a general entitlement to secession; nor did it answer the question of the legal consequences of the declaration of independence or whether Kosovo has become an independent state" 43 .

Si se aplica este razonamiento al caso de Ucrania, se concluye que, pese a que el referéndum en Crimea y la declaración de independencia no sean, en sí, contrarios al derecho internacional, de ello no deriva ninguna consecuencia jurídica respecto de la calidad estatal de Crimea y de la posibilidad consecuente de integrar otro Estado -la Federación de Rusia- por medio de un tratado, entendido como un acuerdo concluido por dos sujetos de derecho internacional. Así, en definitiva, el derecho internacional "no dice nada respecto de la declaración de independencia de parte de una población que se reivindica como pueblo, salvo en el contexto de la descolonización, pero evidentemente no es el caso" ${ }^{44}$ de Crimea.

La ambigüedad del análisis de la Corte podría entenderse en el contexto del argumento elaborado en doctrina sobre la aplicación general del derecho de libre determinación -en cualquiera de sus formas, incluyendo, por lo tanto, la autodeterminación externa-, incluso fuera del contexto de la descolonización. Analizando la opinión consultativa de 2010 de la CIJ, la profesora Carmen López-Jurado Romero de la Cruz afirma, efectivamente, que "la declaración de independencia no se puede entender como otra cosa que como el ejercicio del derecho de autodeterminación" ${ }^{45}$. Asimismo, observando la formulación general de la resolución 2625 (XXV), el profesor Eisemann, sostiene que "en el estado actual del derecho internacional, estos principios consuetudinarios [la integridad territorial y la soberanía del Estado, por un lado, y el derecho a la libre determinación de los pueblos, por el otro] -que generan obligaciones contradictorias para los Estados- tienen el mismo valor jurídico y ninguna regla de conflicto permite hacer primar uno por sobre el otro. En otras palabras,

41 CIJ, Conformité au droit international de la déclaration unilatérale d'indépendance relative au Kosovo (2010) p. 436, párr. 79.

42 CIJ, Conformité au droit international de la déclaration unilatérale d'indépendance relative au Kosovo (2010) pp. 438-438, párr. 84 .

43 MarXsen (2014). Véase, en este sentido, CIJ, Conformité au droit international de la déclaration unilatérale d’indépendance relative au Kosovo (2010) pp. 423-424, párr. 51.

44 Thouvenin (2014).

45 López-Jurado Romero de la Cruz (2011) p. 24. 
estos principios se anulan recíprocamente, privando a los Estados de una prescripción jurídica operacional" ${ }^{\prime 4}$.

Pese a que en 2010 la Corte no basó su conclusión en la aplicación del derecho de autodeterminación, es cierto que la ambigüedad del razonamiento podría explicarse en el intento, calificado de "razonamiento esquivo" 47 en doctrina, de evitar la cuestión extremadamente delicada, desde el punto de vista político, de la gestión de movimientos secesionistas. En este contexto, el argumento doctrinal sobre la primacía, en estos casos, de la solución política, retoma todo su sentido. Pero, incluso si aceptásemos que la solución de la Corte se basa implícitamente en la aplicación del derecho de autodeterminación externa fuera del contexto de la descolonización, una diferencia fundamental subsiste con la situación jurídica de los pueblos colonizados. Estos no requieren de una solución política, pues el derecho de autodeterminación atribuye claramente en estos casos el derecho de independizarse. Por el contrario, en las situaciones fuera de la descolonización, el derecho internacional no apoya la creación de un nuevo Estado sino que se limita a la ausencia de prohibición, lo que explica, precisamente, el debate actual en territorios como Kosovo y eventualmente Crimea.

De esto se deduce que solo la secesión efectuada en perjuicio del Estado colonial es indiscutiblemente apoyada por el derecho internacional. "En este caso, el principio de la integridad territorial no es un obstáculo eficaz, por dos razones fundamentales: la primera, que constituye prácticamente un criterio, reside en la discontinuidad geográfica; la segunda es que la acción no menoscaba realmente una organización estatal en un sentido estricto sino más bien una organización imperial” ${ }^{48}$. Para los otros pueblos, ya sea por medio del argumento doctrinal relativo a la aplicación general del derecho de autodeterminación externa o bien a través del argumento jurisprudencial relativo a la inoponibilidad de los principios protectores del territorio del Estado fuera de las relaciones interestatales, el análisis conduce a una misma constatación: la ausencia de solución jurídica respecto de la existencia del Estado proclamado. Por lo tanto, la solución será otorgada, no por el derecho internacional, sino por la efectividad de la situación, en la cual elementos tanto fácticos como políticos juegan un papel crucial.

Es necesario recordar, en este sentido, que para el derecho internacional la creación del Estado es un fenómeno esencialmente fáctico que reposa sobre la reunión de tres elementos constitutivos: un territorio, una población y un gobierno efectivo e independiente ${ }^{49}$. Así, "ante la ausencia de regla prohibitiva, toda entidad infra-estatal puede intentar una secesión. Si la entidad logra instaurar de manera indiscutible una nueva efectividad, es decir, reunir los 'elementos constitutivos' del Estado, un nuevo Estado podría eventualmente nacer" ${ }^{50}$. Sin embargo, debido al carácter horizontal de la sociedad internacional, la consagración de esta efectividad depende íntimamente de su existencia intersubjetiva

\footnotetext{
46 Eisemann (2010) p. 114.

47 López-Jurado Romero de la Cruz (2011) p. 27.

48 RUiz-FABri (1992) p. 158.

49 Véase, en este sentido, Salmon (2001) p. 454.

50 Christakis (2014) p. 745.
} 
determinada por el reconocimiento de los otros Estados ${ }^{51}$, pues en el orden internacional "cada Estado atesta la significación que atribuye a un cierto hecho" 52 . Esta consagración es particularmente compleja ante los fenómenos de secesión en razón no solo de los motivos políticos que determinan el reconocimiento como acto discrecional ${ }^{53}$, sino también de la necesidad de establecer una "efectividad durable" 54 , capaz de oponerse a la integridad territorial del Estado cuyo territorio está en juego.

Efectivamente, si bien el derecho internacional no prohíbe la secesión, esto no significa que no ofrezca instrumentos al Estado preexistente para oponerse al desprendimiento de una parte de su territorio. Así, en el caso de Crimea, además de los poderes estatales que pueden ser utilizados por Ucrania para apaciguar las reivindicaciones secesionistas -dentro de los límites de las normas internacionales relativas a los derechos humanos, al derecho internacional humanitario y al derecho de la guerra-, la principal protección otorgada por el derecho internacional se desprende del principio de integridad territorial que, pese a no ser oponible a Crimea, constituye una "presunción contra la efectividad de la secesión" 55 . Así, como lo observa el profesor Christakis, el silencio del derecho internacional respecto de la licitud de la secesión no es sinónimo de neutralidad, pues el orden jurídico internacional protege, en principio, la permanencia del Estado ${ }^{56}$.

Por esto, el comportamiento y reconocimiento del Estado preexistente es esencial para el resultado de la secesión ${ }^{57}$, como lo atesta el nacimiento reciente de Sudán del Sur, que proclamó su independencia el 9 de julio de 2011, siendo, desde el día anterior, reconocido por Sudán y admitido, algunos días más tarde, como miembro de la ONU ${ }^{58}$. Por el contrario, si el Estado que experimenta un movimiento secesionista persiste en la negación de la secesión y continúa a tomar medidas para oponerse a la creación del nuevo Estado, será aún más difícil para la entidad secesionista imponer su efectividad frente al principio de integridad territorial, salvo si logra consagrarse de manera tal sobre la escena internacional que su existencia se imponga incluso al Estado preexistente. "Las efectividades juegan, así, sobre todo un rol en la aceptación, o más bien, la resignación del Estado preexistente (que, obligado por la fuerza de los hechos, no tiene otra opción que abandonar sus intentos de recuperación) y no en el nacimiento "automático" de un nuevo Estado" 59.

Cabe destacar, en este sentido, que la violación del derecho interno ucraniano a través de la declaración de independencia no se impone en el orden jurídico internacional, pues la constitución de Ucrania no es una norma sino un hecho para efectos del derecho

\footnotetext{
51 Véase, en este sentido, RuIZ-FABRI (1992) pp. 163-164.

52 Mouton (1992) p. 53.

53 Véase Salmon (2001) p. 938. El caso de Kosovo es ilustrativo en este sentido. La gran mayoría de los Estados miembros de la Unión Europea han reconocido Kosovo, salvo tres Estados entre los cuales figura España y Chipre, ambos afectados por movimientos secesionistas desde hace décadas.

54 Christakis (2014) p. 747.

55 ChristaKis (2014) p. 747.

56 Véase Christakis (2007) pp. 11-12. Véase también, en este sentido, Ruiz-Fabri (1992) pp. 155-169.

57 Véase, en este sentido, Acosta SÁnchez (2014) p. 5.

58 AGNU, A/RES/65/308.

59 Christakis (2007) p. 12
} 
internacional ${ }^{60}$. La posición interna solo puede ser útil a los ojos del derecho internacional cuando conduce a la aceptación de la secesión y al acuerdo del Estado preexistente ${ }^{61}$, como fue el caso de Sudán respecto de Sudán del Sur. Fuera de este contexto, el silencio del derecho internacional no se ve afectado por la violación del derecho interno y solo la efectividad "durable" podrá consagrar la nueva situación. En definitiva, como afirma la Profesora Ruiz-Fabri, "la creación o la desaparición de un Estado son desde el punto de vista del orden internacional perturbaciones contra las cuales el derecho internacional opone principios de resistencia que solo la efectividad puede superar"62.

Por estos motivos, si bien ninguna norma de derecho internacional prohibía a Crimea desprenderse de Ucrania para integrar -solo luego de consagrarse como un Estado independiente- la Federación de Rusia, la definición del resultado del intento secesionista hubiese requerido observar con el tiempo la efectividad "durable" de la situación, ligada entonces al reconocimiento de los otros Estados. Sin embargo, la posibilidad de consagrar la efectividad de la secesión de Crimea sobre la escena internacional se vio impedida desde el origen por la intervención rusa en el conflicto, en violación de las normas fundamentales del derecho internacional. Efectivamente, el carácter ilícito de la situación que dio lugar a la secesión de Crimea creó una obligación de no reconocer la modificación territorial de Ucrania.

\subsection{LA EXCEPCIÓN: LA OBLIGACIÓN DE NO RECONOCER LA ANEXIÓN ILÍCITA DE CRIMEA}

Aun cuando, en principio, el resultado de la secesión de un territorio es determinado por elementos fácticos y de reconocimiento internacional, la primacía de la efectividad por sobre el derecho en esta materia encuentra como límite la conformidad de la acción secesionista con las normas fundamentales del derecho internacional, pues de su violación se deduce una obligación de no reconocer que impide la consolidación de la situación.

\subsubsection{La violación de normas internacionales fundamentales en la secesión de Crimea}

En su opinión consultativa de 2010, la CIJ observó que ciertas declaraciones de independencia han sido declaradas ilícitas por el Consejo de Seguridad, como en los casos de Rhodesia del Sur -respecto de Sudáfrica-, de la República Turca de Chipre del Norte -respecto de Chipre- o bien de la República de Srpska -respecto de la antigua Bosnia y Herzegovina-. La Corte afirmó, sin embargo, que "la ilicitud de estas declaraciones se desprendía entonces no de su carácter unilateral, sino del hecho que estas hayan sido efectuadas a tra-

\footnotetext{
60 Véase Christakis (2014) p. 744, citando la Corte Permanente de Justicia Internacional, Affaire relative à certaines intérêts allemands en Haute-Silésie Polonaise (fond) (1926). La Corte afirma, efectivamente, que "[p]ara el derecho internacional y la Corte que es su órgano, las leyes nacionales son simplemente hechos, manifestaciones de la voluntad y de la actividad de los Estados, tal y como las decisiones de los tribunales y las medidas administrativas" (p. 19).

${ }^{61}$ Véase, en este sentido, Acosta Sánchez (2014) p. 5.

62 Ruiz-Fabri (1992) p. 161.
} 
vés del recurso ilícito a la fuerza armada o por medio de una violación grave de normas de derecho internacional general, sobre todo de naturaleza imperativa (jus cogens)" ${ }^{\text {63 }}$.

En el caso de Crimea, la cuestión de la conformidad al derecho internacional de la acción secesionista tiene directa relación con la participación rusa en el conflicto. Efectivamente, la utilización de la fuerza armada de la parte de Rusia en Ucrania contraviene al artículo 2 párrafo 4 de la Carta de las Naciones Unidas que prohíbe "el recurso a la amenaza o al uso de la fuerza contra la integridad territorial o la independencia política de cualquier Estado". Así, pese a que inicialmente la utilización de la fuerza armada por parte de Rusia no estaba definida, ya se podía considerar el posicionamiento de tropas en la frontera ucraniana a finales de febrero de 2014 como una amenaza de recurso a la fuerza, igualmente prohibida por el derecho internacional.

La situación se esclareció con la petición efectuada por Vladimir Putin al Consejo de la Federación para que este autorizara el despliegue de la armada rusa "en el territorio de Ucrania" ${ }^{64}$. La petición, aprobada por el Consejo el primero de marzo de 2014, se basó en "la extraordinaria situación que tiene lugar en Ucrania y [...] las amenazas contra la vida de ciudadanos rusos, nuestros compatriotas, y miembros del contingente militar de las fuerzas armadas de la Federación de Rusia desplegados de conformidad con el acuerdo internacional en el territorio de Ucrania, la República Autónoma de Crimea"65. Efectivamente, es necesario recordar que Sebastopol -ciudad principal de Crimea- alberga una base naval rusa en virtud de un tratado firmado en 1997 entre Rusia y Ucrania previsto por una duración inicial de veinte años y reconducido en 2010 por treinta años más. Así, sobre el fundamento de la protección tanto de la población rusa en Crimea como de los militares presentes en Sebastopol, Rusia desplegó sus tropas en Ucrania, cuya presencia en Crimea ha sido admitida por las autoridades rusas ${ }^{66}$, mientras que el despliegue en las regiones del este continúa siendo negado.

Si bien en derecho internacional existe un principio general de prohibición de recurso a la fuerza, la acción de la armada rusa en Ucrania debe ser estudiada en el marco de las excepciones y las posibles justificaciones que serían conformes al orden jurídico internacional. Por un lado, el principio conoce dos excepciones: la autorización del Consejo de Seguridad sobre la base del artículo 42 de la Carta de las Naciones Unidas y el derecho de legítima defensa consagrado en el artículo 51 de la Carta. En ausencia de una autorización del Consejo de Seguridad, Rusia invocó un argumento relativo a la protección de la población rusa y de las tropas rusas que insinúa el ejercicio de la legítima defensa. Debido a la debilidad de este argumento, Rusia se basó igualmente en la existencia de una petición de Viktor Yanukovych para intervenir en Ucrania, considerando que la invitación de las autoridades oficiales de un Estado descartan, efectivamente, la violación de su soberanía y de la prohibición del recurso de la fuerza contra su integridad territorial.

63 CIJ, Conformité au droit international de la déclaration unilatérale d'indépendance relative au Kosovo (2010) p. 437, párr. 81.

${ }^{64}$ CSNU, S/PV.7124, p. 5.

65 CSNU, S/PV.7124, p. 5.

66 CSNU, S/PV.7125, pp. 16-17. 
a) El argumento del derecho de legítima defensa respecto de las tropas rusas y de la población rusa en Ucrania

El artículo 51 de la Carta de las Naciones Unidas -que consagra una norma consuetudinaria ${ }^{67}$ - precisa que el derecho de legítima defensa se aplica solamente como respuesta a un "ataque armado contra un Miembro de las Naciones Unidas" ${ }^{68}$. El ataque armado -o "agresión armada” en la versión francesa de la Carta- fue definido por la Asamblea General de la ONU en su resolución 3314 (XXIX) de 1974 como "el uso de la fuerza armada por un Estado contra la soberanía, la integridad territorial o la independencia política de otro Estado, o en cualquier otra forma incompatible con la Carta de las Naciones Unidas" ${ }^{\prime \prime}$, formulación que fue retomada por la definición de la agresión en el marco de la Corte Penal Internacional7 ${ }^{70}$. La noción de agresión ha sido también esclarecida por la CIJ que ha distinguido "entre las formas más graves de recurso a la fuerza (aquéllas que constituyen una agresión armada) y las otras modalidades menos brutales" 71 , precisando, además, que la carga probatoria sobre la existencia de una agresión recae sobre el Estado que invoca el derecho de legítima defensa ${ }^{72}$.

La resolución 3314 (XXIX) contiene ejemplos de casos de agresión -dentro de una lista que no es exhaustiva ${ }^{73}-$, incluyendo, como lo ha señalado Daniel Wisehart, la hipótesis de una agresión extraterritorial ${ }^{74}$. El texto considera, efectivamente, que el "ataque por las fuerzas armadas de un Estado contra las fuerzas armadas terrestres, navales o aéreas de otro Estado, o contra su flota mercante o aérea"75 constituye un acto de agresión. Por esto, se debe determinar si la base naval rusa en Sebastopol sufrió un ataque armado de la parte de Ucrania que pudiese justificar el ejercicio de la legítima defensa para proteger a los "miembros del contingente militar de las fuerzas armadas de la Federación de Rusia desplegados de conformidad con el acuerdo internacional en el territorio de Ucrania”.

Sin embargo, pese a la advertencia lanzada por el gobierno ucraniano para que las tropas rusas permanecieran en el territorio de Crimea autorizado por el tratado, ningún ataque fue invocado por Rusia -Estado sobre el cual recae la carga probatoria- ni identificado por otros medios, previo al despliegue de la armada rusa en Crimea. Más aún, incluso suponiendo la existencia de ataques aislados, el umbral de intensidad definido por la CIJ implica que este tipo de incidentes no bastan para sostener jurídicamente la intervención armada en el territorio ucraniano.

\footnotetext{
67 CIJ, Activités militaires et paramilitaires au Nicaragua et contre celui-ci (Nicaragua c. États-Unis d'Amérique), fond (1986) p. 94, párr. 176.

68 Carta de las Naciones Unidas, art. 51.

69 AGNU, A/RES/3314 (XXIX), art. 1.

70 Estatuto De Roma, art. 8 bis (adoptado el 11 de junio de 2010).

71 CIJ, Activités militaires et paramilitaires au Nicaragua et contre celui-ci (Nicaragua c. États-Unis d'Amérique), fond (1986) p. 101, párr. 191.

72 CIJ, Plates-formes pétrolières (République Islamique d'Iran c. États-Unis d’Amérique) (2003) p. 189, párr. 57.

73 AGNU, A/RES/3314 (XXIX), art. 4.

74 WisEHART (2014).

75 AGNU, A/RES/3314 (XXIX), art. 3,d.
} 
Por esto, se debe analizar el segundo argumento elaborado por Rusia con respecto a la aplicación del derecho de legítima defensa a la protección de la población rusa en Ucrania $-y$ no a la población ucraniana ruso-parlante ${ }^{76}$, tema que ha sido, desde hace décadas, objeto de debates en doctrina ${ }^{77}$. El estudio detallado del profesor Tom Ruys demuestra, no obstante, que el comportamiento de los Estados en la materia es equívoco -las tesis doctrinales que apoyan la existencia de dicha norma se refieren principalmente a operaciones de rescate de rehenes e incluyen operaciones en las cuales el Estado cuyo territorio fue el objeto de la intervención había consentido- y que, de todas formas, no existe un consenso con respecto a la obligatoriedad de tal conducta por lo que falta la opinio iuris necesaria para la emergencia de una costumbre internacional ${ }^{78}$. Más aún, incluso suponiendo la existencia de tal aplicación de la legítima defensa, los autores que la sostienen condicionan su ejercicio a circunstancias particulares, como el límite de la respuesta a la adopción de medidas estrictamente necesarias para realizar dicha protección ${ }^{79}$.

Cabe destacar que, en cualquier caso, el derecho internacional consuetudinario exige que el ejercicio de la legítima defensa cumpla con las condiciones de proporcionalidad y necesidad ${ }^{80}$. Por lo mismo, si bien la aplicación del derecho de legítima defensa a la protección de la población rusa o de los militares rusos en Ucrania es extremadamente dudosa, aun cuando tal derecho hubiese existido, la intervención rusa en Ucrania debiera haber sido necesaria y proporcional al daño incurrido. Sin embargo, cuando la intervención rusa fue aprobada por el Consejo de la Federación ningún daño había sido establecido en este sentido. Es más, la aprobación del recurso a la fuerza no fue solicitada solamente respecto de Crimea ni de los territorios que albergan a nacionales o militares rusos, sino respecto de todo el territorio ucraniano, lo que se opone directamente a las condiciones consuetudinarias de necesidad y proporcionalidad de la respuesta.

Por estos motivos, la intervención rusa en Ucrania no puede ser justificada sobre la base de la legítima defensa. El carácter altamente cuestionable del argumento explica precisamente que el gobierno ruso haya cambiado el enfoque principal de su justificación intentando demostrar la existencia de une invitación oficial de la parte de Ucrania para intervenir en su territorio.

\footnotetext{
${ }_{76}$ Si se tratara de la población ucraniana ruso-parlante, la cuestión sería aquella de la "responsabilidad de proteger". Este argumento fue solamente esbozado por Rusia durante las discusiones en el Consejo de Seguridad, donde el representante ruso afirmó que la acción de su país pretendía "defender a nuestros ciudadanos y compatriotas, así como [...] defender el derecho humano más importante, que es el derecho a la vida" (CSNU, S/ PV.7125, p. 3). La consagración de la responsabilidad de proteger se limita, sin embargo, a declaraciones políticas (véase particularmente el Documento Final de la Cumbre Mundial de 2005 en AGNU, A/RES/60/1, párr. 138-139) sin constituir un fundamento jurídico independiente para el recurso a la fuerza armada ni menos una obligación de la comunidad internacional en este sentido, como lo demuestra, por ejemplo, la ausencia de intervención en Siria. Véase, en este sentido, Pellet (2013) pp. 185-191.

77 Wisehart (2014).

78 Véase, de manera general, RuYs (2008), en particular pp. 260-263.

79 Véase, por ejemplo, WALDOCK (1952) p. 467.

${ }^{80} \mathrm{CIJ}$, Activités militaires et paramilitaires au Nicaragua et contre celui-ci (Nicaragua c. États-Unis d'Amérique), fond (1986) p. 103, párr. 194.
} 
b) El argumento de la invitación oficial de la parte de Ucrania

Frente a la debilidad de la justificación de la legítima defensa, Rusia intentó basar jurídicamente su intervención en una supuesta invitación formulada tanto por Viktor Yanukovych en su calidad de Presidente de Ucrania, como por las autoridades de Crimea. El primero de marzo de 2014 el representante de la Federación Rusa ante el Consejo de Seguridad afirmó que "el Primer Ministro de Crimea, Sr. Aksyonov, se dirigió al Presidente de Rusia para solicitarle asistencia a fin de restablecer la paz en Crimea. De acuerdo con la información disponible, la solicitud también recibió el apoyo del Sr. Yanukovych, cuya destitución, a nuestro juicio, fue ilegal”" Dos días más tarde, Rusia explicó nuevamente ante el Consejo de Seguridad la solicitud formulada por las autoridades de Crimea y de Ucrania, afirmado esta vez que disponía de una carta firmada por Viktor Yanukovych ${ }^{82}$.

Efectivamente, las autoridades oficiales de un Estado pueden solicitar la ayuda militar de un Estado extranjero, lo que no constituye, entonces, una “intervención” contraria a la soberanía e integridad territorial del Estado en cuestión. Ejemplos recientes de este tipo de peticiones son proporcionados por la solicitud de ayuda militar formulada por la República Centroafricana y por Malí a Francia en 2013, que recibieron una respuesta positiva de la parte de las autoridades francesas. Sin embargo, como lo ha afirmado la CIJ, la solicitud debe provenir de las autoridades oficiales del Estado, pues el principio de no intervención, de valor consuetudinario, "perdería toda su significación como principio de derecho si la intervención pudiese estar justificada en una simple petición de ayuda formulada por un grupo de oposición en otro Estado" ${ }^{83}$.

Así, se debe descartar inmediatamente la petición realizada por las autoridades separatistas de Crimea como fundamento jurídico de la intervención rusa en Ucrania, pues estas autoridades representan solamente a una parte del territorio dentro del orden jurídico interno ucraniano, reduciéndose, para efectos del derecho internacional, a un grupo de oposición. La duda, no obstante, podría subsistir respecto de la petición de Viktor Yanukovych en su supuesta calidad de representante de Ucrania en el orden internacional. Es precisamente sobre este plano que se ha situado la argumentación rusa, insistiendo en la ilegalidad de las nuevas autoridades ucranianas, que habrían realizado un verdadero golpe de Estado ${ }^{84}$. Por esto, según Rusia, la invitación de Viktor Yanukovych es válida respecto del derecho internacional aun cuando de facto este ya no estaba ejerciendo el cargo de Presidente cuando la formuló.

Cabe destacar, en este sentido, como lo recuerda el profesor Wisehart ${ }^{85}$, que ya en 1957 el Comité Especial sobre el Problema de Hungría de la Asamblea General de la ONU afirmaba que " $[t]$ he act of calling in the forces of a foreign State for the repression of internal disturbances is an act of so serious a character as to justify the expectation that no uncertainty should be allowed to exist regarding the actual presentation of such a request by a

81 CSNU, S/PV.7124, p. 5.

82 Véase CSNU, S/PV.7125, pp. 3-4.

83 CIJ, Activités militaires et paramilitaires au Nicaragua et contre celui-ci (Nicaragua c. États-Unis d'Amérique), fond (1986) p. 126, párr. 246.

${ }^{84}$ Véase CSNU, S/PV.7125, pp. 16-17.

85 Véase Wisehart (2014). 
duly constituted Government" ${ }^{\prime 6}$. Si bien ejemplos recientes muestran que se ha utilizado la fuerza armada en beneficio de regímenes destituidos -como en el caso de Haití en 1994, de Sierra León en 1998 y de Costa de Marfil en 2011-, el verdadero fundamento jurídico en estos casos no fue la invitación de las autoridades "legales" destituidas de facto sino la intervención autorizada por el Consejo de Seguridad sobre la base del capítulo VII de la Carta de las Naciones Unidas ${ }^{87}$.

Así, aun suponiendo que Viktor Yanukovych efectivamente formuló la petición a Rusia el primero de marzo de 2014, su calidad de representante oficial del Estado ucraniano en el orden internacional en aquel momento no puede ser establecida de manera indiscutida, puesto que su paradero se desconocía y que otra persona se encontraba ejerciendo la función de Presidente de Ucrania. La supuesta invitación de Viktor Yanukovych no puede considerarse entonces como una justificación para la acción militar rusa en Ucrania.

Por estos motivos, la presencia de tropas rusas en Ucrania constituye una violación de la prohibición del recurso a la fuerza armada y, en conformidad con la definición de la Asamblea General, un verdadero acto de agresión ${ }^{88}$. Más aún, la injerencia por este medio y la anexión consecutiva de Crimea constituyen, simultáneamente, una violación de la soberanía ucraniana, del principio de no intervención en los asuntos internos de otro Estado, de la intangibilidad de las fronteras y de la integridad territorial ${ }^{89}$.

Así, en el caso de Crimea, " $[t]$ he violation of international law then does not stem from the unilateral character of the declaration of independence, but from its reliance on the violation of a peremptory norm of international law" ${ }^{\prime 0}$. Esta violación otorga un carácter ilícito a la secesión del territorio y a su integración a Rusia, dando origen, en derecho internacional, a una obligación de no reconocer la situación.

\subsubsection{La obligación de no reconocer la anexión de Crimea}

Si bien el reconocimiento de un nuevo Estado es un acto discrecional, excepcionalmente los Estados están obligados de no reconocer la nueva situación en razón de la violación de las normas fundamentales del derecho internacional en la que su nacimiento se enmarca. Así, en las referencias citadas por la CIJ en 2010 -Rhodesia del Sur, la República Turca de Chipre del Norte y la República de Srpska- el Consejo de Seguridad decidió, sobre la base del capítulo VII de la Carta de las Naciones Unidas, que los Estados tenían una obligación de no reconocer la nueva entidad ${ }^{91}$. Otros ejemplos pueden ser señalados, como

86 ONU (1957) p. 79, párr. 266.

87 Véase Fox (2014).

88 AGNU, A/RES/3314 (XXIX), art. 3, a et e. Véase, en este sentido, VIDMAR (2014).

${ }^{89}$ La violación, en este aspecto, del derecho internacional se refleja claramente en las disposiciones de la resolución 2625 (XXV) de la Asamblea General de la ONU que, afirmando el derecho de libre determinación de los pueblos, precisa simultáneamente que "[t]odo Estado se abstendrá de cualquier acción dirigida al quebrantamiento parcial o total de la unidad nacional e integridad territorial de cualquier otro Estado o país" (AGNU, A/ RES/2625 (XXV), anexo).

90 MARXSEN (2014).

91 Véase respecto de Sudáfrica, S/RES/216 (1965), párr. 2; respecto de Chipre, S/RES/541 (1983), párr. 7; respecto de Bosnia y Herzegovina, S/RES/787 (1992), párr. 3 (el Consejo utiliza, sin embargo, una terminología menos clara que en los ejemplos anteriores). 
la obligación de no reconocer la anexión de Kuwait efectuada por Iraq a través de la fuerza armada durante la Segunda Guerra del Golfo ${ }^{92}$.

En 2010, sin embargo, la Corte declaró que en "en el caso de Kosovo, el Consejo de Seguridad no ha adoptado nunca esta posición"93. De esta afirmación se podrían deducir dos conclusiones. Primero, se podría pensar que la obligación de no reconocer la situación creada de manera ilícita solo nace por medio de una resolución del Consejo de Seguridad sobre la base del capítulo VII de la Carta de las Naciones Unidas ${ }^{94}$. En segundo lugar, se podría concluir que, pese a la existencia de tal obligación fuera del marco de una resolución del Consejo, la constatación de la ilicitud por este medio es necesaria para que nazca la obligación de no reconocer. Con estos razonamientos, el bloqueo del Consejo de Seguridad por parte de Rusia en el caso de Crimea ${ }^{95}$ constituiría un obstáculo doble al nacimiento de la obligación de no reconocer la anexión de Crimea.

Con respecto al primer argumento, relativo al nacimiento de la obligación de no reconocer, se ha señalado en doctrina que la Corte, refiriéndose a una acción del Consejo de Seguridad sobre la base del capítulo VII de la Carta de las Naciones Unidas, "hac[e] descansar el respeto del principio de la integridad territorial en una decisión que depende de un órgano político sometido a la posibilidad de ejercicio del derecho de veto por parte de sus miembros permanentes" ${ }^{\prime 2}$. No obstante, la obligación de no reconocer forma, en realidad, parte del derecho internacional consuetudinario, por lo que no necesita la fuerza jurídica de una decisión del Consejo de Seguridad para imponerse a los Estados ${ }^{97}$.

Respecto del segundo argumento, relativo a la constatación de la ilicitud al origen de la situación, no es necesario, tampoco que esta sea centralizada a través del Consejo de Seguridad. El profesor Christakis realiza un paralelo, en este sentido, con los Artículos sobre la responsabilidad del Estado por hechos internacionalmente ilícitos de la Comisión de Derecho Internacional, donde la obligación de no reconocer la situación creada a partir de la violación grave de normas imperativas del derecho internacional no está subordinada a la existencia de un procedimiento institucional ${ }^{98}$. Con todo, la constatación centralizada por medio del Consejo de Seguridad conserva la utilidad de imponer a los Estados una posición colectiva sobre la apreciación de la ilicitud de la situación. Pero la ausencia de tal resolución no impide que la obligación de no reconocer la anexión de Crimea se imponga a todos los Estados en conformidad con el derecho internacional.

Por esto, a diferencia de la situación de Kosovo, el orden jurídico internacional no es silencioso en el caso de Crimea. Contrariamente a lo que se ha señalado en doctrina ${ }^{99}$, la

\footnotetext{
92 Véase CSNU, S/RES/662 (1990).

93 CIJ, Conformité au droit international de la déclaration unilatérale d'indépendance relative au Kosovo (2010) p. 437, párr. 81 .

94 Véase infra a propósito de la fuerza jurídica de las resoluciones del Consejo de Seguridad sobre la base del capítulo VII de la Carta de las Naciones Unidas.

95 Véase infra a propósito del bloqueo del Consejo de Seguridad respecto de la situación en Crimea.

96 López-Jurado Romero de la Cruz (2011) p. 23.

97 Véase Bismuth (2014) p. 724, Christakis (2006) pp. 127-166, Vidmar (2014).

98 Christakis (2006) p. 131. Véase AGNU, A/RES/56/83, arts. 40 y 41.

99 Goldsmith (2014).
} 
distinción esencial entre Kosovo y Crimea no se sitúa en el marco político de la legitimidad de la secesión, sino en el marco jurídico de la conformidad al derecho internacional de las acciones secesionistas. Esto explica que el reconocimiento de la independencia de Crimea y de su anexión a Rusia sea ilícito, mientras que, en el caso de Kosovo, el derecho internacional no impone una solución y el reconocimiento conserva su carácter esencialmente discrecional, y determinado por factores políticos.

Ambas situaciones, sin embargo, se acercan cuando se trata de evaluar el peso de la política en el resultado final del intento secesionista. Efectivamente, la gran paradoja en el caso de Crimea es que, pese a la violación de normas fundamentales del derecho internacional cuya constatación no depende de la acción del Consejo de Seguridad, el bloqueo de este trae como resultado un carácter extremamente restringido de la reacción internacional.

\section{LOS LÍMITES JURÍDICOS DE LA REACCIÓN INTERNACIONAL ANTE LA ANEXIÓN ILÍCITA DE CRIMEA}

Debido al bloqueo del Consejo de Seguridad de la ONU en razón de la calidad de miembro permanente de Rusia, que será analizado en un primer apartado, la reacción internacional frente a la anexión de Crimea se reduce a la obligación de no reconocer y a la eventual adopción de "sanciones". Sin embargo, ambas acciones tienen un alcance profundamente limitado desde el punto de vista jurídico, cuyo análisis será el objeto de un segundo apartado.

\subsection{El bloqueo del Sistema de Seguridad colectiva de las Naciones Unidas}

Basta recordar, en estas líneas, que la composición del Consejo de Seguridad de las Naciones Unidas, directamente determinada por el resultado de la Segunda Guerra Mundial, establece una distinción fundamental entre los cinco miembros permanentes -China, Estados Unidos, Francia, el Reino Unido y Rusia- y los diez miembros no permanentes ${ }^{100}$. Además de la continuidad en el mandato, los miembros permanentes del Consejo disponen del "derecho al veto" que no es, sin embargo, previsto por el acto constitutivo de la ONU, sino que surgió de una norma consuetudinaria que modificó la letra de la Carta ${ }^{101}$. Así, toda resolución del Consejo de Seguridad sobre una cuestión de fondo debe ser adoptada por nueve votos sobre quince ${ }^{102} \mathrm{y}$ sin oposición de un miembro permanente.

\footnotetext{
100 Los miembros no permanentes, de los cuales forma parte Chile desde el 1 de enero de 2014 hasta el 31 de diciembre de 2016, son renovados por mitad cada dos años por la Asamblea General de la ONU, según una repartición geográfica predefinida (véase AGNU, A/RES/1991 (XVIII)).

101 El artículo 27 párr. 3 de la Carta de las Naciones Unidas establece la necesidad -cuyo estándar es más exigente que el derecho al veto- del voto afirmativo de todos los miembros permanentes para adoptar una resolución sobre una cuestión de fondo. Por esto, desde los primeros años de funcionamiento de la Organización y para protestar frente a la representación de China ante la ONU por Taiwán, Rusia decidió abstenerse de asistir al Consejo de Seguridad para impedir la adopción de cualquier resolución. Pese a esto, el Consejo adoptó resoluciones respecto de la guerra en Corea, lo que dio lugar a una norma consuetudinaria que modificó la letra de la Carta de las Naciones Unidas como lo reconoció posteriormente la CIJ (véase CIJ, Conséquences juridiques pour les États de la présence continue de l'Afrique du Sud en Namibie (Sud-Ouest africain) nonobstant la résolution 276 (1970) du Conseil de sécurité (1971) p. 22, párr. 22).

102 Carta de las Naciones Unidas, art. 27, párr. 3.
} 
Las reglas relativas al voto en el Consejo de Seguridad explican que, dada la implicación rusa en el caso de Crimea, ninguna resolución haya sido adoptada durante el año 2014 a propósito del conflicto en Ucrania, salvo respecto del derribo de un avión comercial de Malaysia Airlines solo algunos días después de la firma del primer acuerdo de Minsk ${ }^{103}$. Recientemente, tras la conclusión de los Acuerdos de Minsk 2, se logró adoptar por unanimidad la resolución 2202 (2015). En el texto, presentado por Rusia, el Consejo "[h]ace suyo" ${ }^{104}$ el conjunto de medidas contenido en los Acuerdos, que figuran en el anexo de la resolución. Esta no se refiere, sin embargo, en ningún momento a la situación territorial de Crimea, limitándose a las condiciones del alto al fuego "en ciertas zonas de las regiones ucranianas de Donetsk y Lugansk"105. Con respecto a Crimea, el representante de la Federación rusa ante las Naciones Unidas ha sido tajante al afirmar que "[n]o analizaremos la situación en Crimea en el Consejo de Seguridad, al menos no en el contexto de la situación en Ucrania” ${ }^{106 .}$

La calidad de miembro permanente de Rusia en el Consejo de Seguridad explica, efectivamente, que haya habido solo una tentativa de proyecto de resolución a propósito de la independencia y de la anexión de Crimea, cuyo voto se realizó un día antes del referéndum. El 15 de marzo de 2014, se presentó ante el Consejo un proyecto patrocinado por cuarenta y dos países que, reafirmando la integridad territorial de Ucrania, declaraba que "ese referéndum no puede tener validez y no puede servir de base para ninguna alteración del estatuto de Crimea; y exhorta[ba] a todos los Estados, las organizaciones internacionales y los organismos especializados a no reconocer alteración alguna del estatuto de Crimea sobre la base de ese referéndum" ${ }^{107}$. Como era de esperarse, el proyecto no pudo ser adoptado pues, si bien recibió trece votos a favor -China se abstuvo-, Rusia votó en contra utilizando su derecho al veto. Ante el bloqueo del Consejo de Seguridad, la Asamblea General de la ONU adoptó el 27 de marzo de 2014 una resolución que retoma esencialmente el contenido del proyecto rechazado en el Consejo, declarando inválido el referéndum ya realizado y reiterando la obligación de no reconocer la modificación territorial de Ucrania ${ }^{108}$.

Cabe destacar que la fuerza jurídica de la resolución de la Asamblea General no es la misma que aquella que hubiese tenido el proyecto presentado ante el Consejo de Seguridad de haber sido adoptado. En efecto, la Asamblea solo puede efectuar "recomendaciones"109, mientras que el Consejo puede adoptar, sobre la base del capítulo VII de la Carta de las Naciones Unidas, "decisiones" cuya fuerza es vinculante, imponiéndose así a todos los Estados miembros de la Organización ${ }^{110}$. Esta distinción se explica por la "responsabilidad primordial de mantener la paz y la seguridad internacionales" 111 atribuida al Consejo de Seguridad por la Carta, que creó, por este medio y como corolario de la prohibición general

\footnotetext{
103 CSNU, S/RES/2166 (2014).

104 CSNU, S/RES/2202 (2015), párr. 1.

05 CSNU, S/RES/2202 (2015), anexo 1, párr. 1.

106 CSNU, S/PV.7157, p. 22.

107 CSNU, S/2014/189, párr. 5.

108 AGNU, A/RES/68/262.

109 Carta de las Naciones Unidas, art. 10.

110 Carta de las Naciones Unidas. art. 25.

111 Carta de las Naciones Unidas. art. 24, párr. 1.
} 
de recurso a la fuerza, un "sistema de seguridad colectiva". Por esto, además de un poder de recomendación -en el contexto del capítulo VI de la Carta relativo a la solución pacífica de controversias-, la Carta atribuye al Consejo un poder de decisión para hacer frente a una "amenaza a la paz, quebrantamiento de la paz o acto de agresión"112.

Para restablecer la seguridad internacional ante estas situaciones, el capítulo VII de la Carta de las Naciones Unidas ofrece al Consejo la posibilidad de adoptar medidas que implican o no el recurso a la fuerza $\operatorname{armada}^{113}$, sin enumerarlas de manera limitativa. El carácter indicativo de los ejemplos proporcionados ha dado lugar a una evolución creativa por parte del Consejo particularmente en el contexto de la lucha internacional contra el terrorismo que, junto a la voluntad de disminuir el impacto negativo de la acción sobre la población civil, ha motivado la adopción de sanciones "selectivas" o "inteligentes"114. Así, junto con el empleo tradicional de medidas económicas restrictivas, se han adoptado medidas más focalizadas como el embargo de armas y la prohibición de viaje o la congelación de activos de las personas inscritas en las listas elaboradas por el Consejo a través de los comités de sanciones.

En razón del carácter obligatorio para todos los Estados miembros de la ONU de las medidas decididas por el Consejo de Seguridad sobre la base del capítulo VII de la Carta, estas acciones representan la manera más eficaz de reaccionar frente a las situaciones ilícitas que amenazan la paz y la seguridad internacionales, más aún considerando que las decisiones del Consejo se imponen incluso frente a las otras obligaciones convencionales de los Estados miembros. Efectivamente, el artículo 103 de la Carta de las Naciones Unidas prevé que "[e]n caso de conflicto entre las obligaciones contraídas por los Miembros de las Naciones Unidas en virtud de la presente Carta y sus obligaciones contraídas en virtud de cualquier otro convenio internacional, prevalecerán las obligaciones impuestas por la presente Carta”. Así, un Estado miembro de la ONU no puede invocar, por ejemplo, sus obligaciones en virtud del Acuerdo General sobre Aranceles Aduaneros y Comercio (GATT) de la Organización Mundial del Comercio (OMC) para no ejecutar una medida económica restrictiva decidida por el Consejo de Seguridad.

El carácter extremadamente particular en derecho internacional de las medidas decididas por el Consejo de Seguridad explica que su bloqueo en el caso de Crimea sea tan problemático para la eficacia de la reacción internacional. Si bien esta situación no es determinante con respecto al nacimiento de la obligación de no reconocer, puesto que la norma existe fuera del marco institucional y convencional de la ONU, el bloqueo adquiere todo su peso cuando se trata de tomar "medidas" para restablecer la soberanía de Ucrania en Crimea, como lo demuestra, por ejemplo, la eficacia del sistema de seguridad colectiva ante la anexión de Kuwait por Iraq en $1990^{115}$. Sin embargo, frente al bloqueo del Consejo de Seguridad en el caso de Crimea, la reacción internacional se ve reducida a la acción descentralizada de los Estados -ya sea de manera individual o a través de organizaciones internacionales-, cuyo límite jurídico es impuesto por el carácter de "tercero" en el conflicto.

\footnotetext{
112 Carta de las Naciones Unidas art. 39.

113 Carta de las Naciones Unidas. arts. 42 y 41 respectivamente.

114 Véase, por ejemplo, Wilson (2014) pp. 83-115.

115 Véase, particularmente, S/RES/678 (1990) y S/RES/687 (1991).
} 


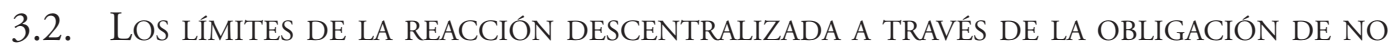
RECONOCER Y DE LAS SANCIONES INTERNACIONALES

Frente al bloqueo del Consejo de Seguridad de la ONU, solo restan la obligación de no reconocer -norma que se impone a todos los Estados- y las medidas facultativas que pueden adoptar los Estados, ya sea individualmente o colectivamente, bajo la forma de "sanciones internacionales".

Respecto de la obligación de no reconocer, se ha señalado en doctrina que "una vez anexionada, [Crimea] formará parte integral de Rusia y el Estado que la desconozca tendrá que desconocer a Rusia misma"116. Sin embargo, esta afirmación no es correcta desde un punto de vista jurídico, pues la obligación de no reconocer tiene un alcance limitado que explica, precisamente, el carácter problemático del bloqueo del Consejo de Seguridad en el caso de Crimea. En efecto, la obligación de no reconocer cubre solo los actos que impliquen reconocer a Crimea como parte del territorio de la Federación de Rusia. Así, por ejemplo, los Estados pueden -y deben pues se trata de una obligación en derecho internacional- rechazar los pasaportes rusos emitidos en Crimea, pero no pueden extender el rechazo a los otros pasaportes rusos. De la misma manera, los Estados tienen la obligación de rechazar las importaciones provenientes de Crimea efectuadas por Rusia, pero no pueden extender el rechazo a las otras importaciones rusas si es que están obligados, por ejemplo, por las normas adoptadas en el marco de la OMC, salvo si es que existe la posibilidad de invocar ciertas excepciones dentro del marco convencional ${ }^{117}$. En definitiva, el objeto de la obligación no es, bajo ninguna circunstancia, el reconocimiento de Rusia, sino tan solo de la "Crimea rusa".

El alcance limitado de la obligación de no reconocer explica que ciertos Estados y organizaciones internacionales hayan adoptado, simultáneamente, "sanciones" contra personas rusas, personas ucranianas y la Federación de Rusia, con el fin de ejercer una presión contra la anexión ilícita de Crimea. En este sentido, si bien el carácter ilícito de la situación ha sido denunciado por varios Estados y organizaciones internacionales -como la OTAN y la Organización por la Seguridad y la Cooperación en Europa (OSCE) ${ }^{118}$-, las sanciones han sido principalmente adoptadas por Estados Unidos y la Unión Europea, siguiendo una lógica de progresividad frente a la intensificación del conflicto. En ambos casos, no obstante, las sanciones se han limitado a la adopción de medidas de retorsión, lo que se explica por la posición de "tercero" en el conflicto.

Efectivamente, la reacción frente al hecho ilícito en el orden jurídico internacional puede realizarse a través de la adopción de medidas de retorsión o bien de contramedidas. La distinción entre ambas categorías reside en la conformidad per se de la medida al derecho internacional. Las medidas de retorsión son intrínsecamente lícitas, mientras que las contramedidas son acciones intrínsecamente ilícitas cuya conformidad al derecho internacional es proporcionada por su calidad de respuesta al hecho ilícito previo ${ }^{119}$, debiendo

\footnotetext{
116 RodrígueZ-SantibáÑEZ (2014).

117 Véase Bismuth (2014) p. 725, analizando particularmente la posibilidad de invocar las "excepciones relativas a la seguridad" previstas por el artículo XXI del GATT.

118 Véase Acosta SÁnchez (2014) pp. 11-13.

119 AGNU, A/RES/56/83, art. 22.
} 
tener, entonces, como único fin la cesación del hecho ilícito ${ }^{120}$. Esta distinción explica que, si bien todos los Estados pueden adoptar medidas de retorsión contra Rusia por la anexión de Crimea -la retorsión siendo, en este sentido, no tanto un instrumento jurídico sino más bien político-, solo el Estado lesionado, es decir Ucrania, puede adoptar contramedidas contra la Federación rusa en su calidad de Estado responsable de la violación del derecho internacional ${ }^{121}$.

La limitación de la reacción internacional, en el caso de Crimea, a las medidas de retorsión es evidenciada en las sanciones adoptadas por la Unión Europea en el marco de la Política Exterior y de Seguridad Común (PESC). Estas “medidas restrictivas”, previstas por el Tratado de Funcionamiento de la Unión Europea ${ }^{122}$, se basan en dos decisiones aprobadas por el Consejo de la Unión Europea el 5 de marzo y el 17 de marzo de 2014.

La primera decisión fue adoptada solo algunos días después de la destitución de Viktor Yanukovych y se refiere de manera general a "la situación en Ucrania"123. Su fin es inmovilizar y recuperar los activos de "personas que hayan sido identificadas como responsables de la apropiación indebida de fondos del Estado ucraniano y [de] personas responsables de violaciones de los derechos humanos en Ucrania, o [de] personas físicas o jurídicas, entidades u organismos asociados con ellas" ${ }^{124}$, particularmente durante las manifestaciones pro-Unión Europea de finales de 2013 -en la práctica el ex-Presidente y sus cercanos-. La segunda decisión fue adoptada por el Consejo dos días después del referéndum en Crimea, lo que explica el establecimiento de "medidas restrictivas respecto de acciones que menoscaban o amenazan la integridad territorial, la soberanía y la independencia de Ucrania"125. Estas medidas prevén, por un lado, la suspensión de las negociaciones entre la Unión Europea y Rusia en materia de visados y de la actualización del Acuerdo de colaboración y cooperación de $1998^{126}$ y, por el otro, "restricciones en materia de viaje y la inmovilización de activos a personas responsables de acciones que menoscaben o amenacen la integridad territorial, la soberanía y la independencia de Ucrania, incluidas acciones sobre el futuro estatuto de cualquier parte del territorio que sean contrarias a la Constitución ucraniana, y a personas, entidades u organismos asociadas a ellas" ${ }^{127}$. Sobre la base de estos dos actos, se establecieron listas de las personas afectadas por las medidas restrictivas, que fueron completadas por decisiones posteriores del Consejo de la Unión Europea.

Si bien las sanciones adoptadas en el marco de la Unión Europea tienen un impacto certero sobre la propiedad de las personas listadas y podrían ser consideradas ilícitas sobre la base de ciertos derechos garantizados, por ejemplo, en la Convención Europea de Derechos Humanos -en la cual los 28 Estados miembros de la Unión, Ucrania y Rusia son partes-, Charlotte Beaucillon observa que las normas internacionales reglamentan solamente las con-

120 AGNU, A/RES/56/83, art. 49, párr. 1.

121 AGNU, A/RES/56/83, art. 49, párr. 1.

122 Tratado de Funcionamiento de la Unión Europea, art. 215.

123 Consejo de la Unión Europea, Decisión 2014/119/PESC.

124 Consejo de la Unión Europea, Decisión 2014/119/PESC art. 1, párr. 1.

125 Consejo de la Unión Europea, Decisión 2014/145/PESC.

126 Consejo de la Unión Europea, Decisión 2014/145/PESC. preámbulo, párr. 2.

127 Consejo de la Unión Europea, Decisión 2014/145/PESC. preámbulo, párr. 4. 
diciones de aplicación de estas medidas, como la duración y la rigidez, sin prohibir su adopción ${ }^{128}$. Así, se trata de acciones intrínsecamente lícitas en derecho internacional que permanecen dentro del marco de la retorsión. El periodo por el cual fueron adoptadas las medidas es ilustrativo en este sentido pues la duración fue inicialmente prevista por seis meses, dando cuenta de la voluntad de negociar con Rusia y con las autoridades de Crimea ${ }^{129}$.

Efectivamente, las sanciones adoptadas contra Rusia por la anexión de Crimea han sido limitadas no solo desde el punto de vista jurídico - por la prohibición del recurso a las contramedidas, salvo en el caso de Ucrania-, sino también por consideraciones políticas relativas a la posición de Rusia en la escena internacional. Esta posición, evidente en el bloqueo del sistema de seguridad colectiva de las Naciones Unidas, se reproduce en las relaciones bilaterales y multilaterales, donde factores políticos y económicos -por ejemplo, la dependencia de Europa respecto del gas ruso- explican que las "sanciones" tengan por objetivo principal la negociación de una solución política, emergiendo así una verdadera "batalla diplomática a nivel global"130. La reacción de la Unión Europea es interesante en este aspecto pues, además de las sanciones aprobadas contra Rusia, la Organización ha insistido particularmente en la adopción de medidas "positivas" para apoyar económica y técnicamente a Ucrania y reafirmar su acercamiento hacia la Unión ${ }^{131}$.

Por esto, si bien la mayoría de los Estados ha demostrado una voluntad firme de no reconocer la anexión de Crimea a la Federación Rusa, apegándose al respeto del derecho internacional, la rigidez de la obligación de no reconocer, que permite por el momento resistir ante la ilicitud de la situación y ejercer presión sobre Rusia, deberá también, en algún momento, ceder frente a la negociación política si se quiere encontrar una salida al conflicto. Como observa el profesor Christakis, "en el caso de Crimea, como también, sin duda, en otras situaciones problemáticas que envenenan las relaciones internacionales (casos como el de Palestina, Chipre y el Sahara Occidental), solo una solución negociada y libremente aceptada por todos los protagonistas permitirá resolver este conflicto intenso entre efectividades ilícitas y derecho"132, enfrentamiento que está marcado por la relación entre los factores políticos y jurídicos en la aplicación efectiva del derecho internacional.

\section{CONCLUSIONES Y PERSPECTIVAS DE REFLEXIÓN}

El caso de Crimea nos recuerda los límites del derecho internacional no solo frente a la realidad política sino también frente a las desigualdades jurídicamente institucionalizadas dentro de las Naciones Unidas y la violación en cierta medida "impune" de los principios fundamentales del derecho internacional de la parte de los miembros permanentes del Consejo de Seguridad.

\footnotetext{
128 Beaucillon (2014) pp. 803-805.

129 BeAuCillon (2014) pp. 803-805.

130 Boeglin (2014).

131 Véase Martucci (2014) pp. 777-781.

132 Christakis (2014) p. 764.
} 
Efectivamente, no se debe olvidar, como bien recuerda el profesor Marcelo Kohen ${ }^{133}$, que los miembros permanentes del Consejo que han adoptado una posición tajantemente condenatoria respecto de la acción rusa en Crimea han igualmente, en años recientes, violado los principios fundamentales del derecho internacional. Algunos ejemplos son proporcionados por el ataque aéreo de la OTAN en Serbia en 1999 para proteger a la populación kosovar -cuya legitimidad es, sin embargo, en nuestra opinión, mayor a aquella de las otras situaciones discutidas- y las intervenciones, a principios de los años 2000, de Estados Unidos y el Reino Unido en Afganistán e Iraq, sobre la base de fundamentos jurídicos dudosos por no decir inexistentes en el último caso. Esta transgresión se ha podido constatar incluso respecto de casos en que el Consejo de Seguridad había efectivamente autorizado el recurso a la fuerza armada, como lo atesta la intervención en Libia en 2011 en la cual los términos, voluntariamente restringidos de la resolución del Consejo ${ }^{134}$, no fueron respetados. En este aspecto, la situación de Crimea -que no deja de evocar la intervención rusa en Georgia en 2008 con el fin de sostener la independencia de Osetia del Sur- nos recuerda el rol de la política en la aplicación efectiva del derecho internacional, particularmente respecto de la labor de mantenimiento de la paz y la seguridad internacionales confiada primordialmente al Consejo de Seguridad de la ONU.

Esto no significa, sin embargo, que el orden jurídico internacional haya perdido toda su importancia y que debamos refugiarnos completamente en las teorías realistas del derecho internacional. Por el contrario, como ha señalado Nico Krisch, la permanente tentativa de justificación de las autoridades rusas sobre la base del derecho de autodeterminación y del "precedente" de Kosovo demuestra, simultáneamente, que los Estados, incluso los más "poderosos" sobre la escena internacional, atribuyen un rol crucial al derecho internacional ${ }^{135}$. La explotación, no obstante, de argumentos jurídicos debatidos en doctrina -como el alcance del derecho de autodeterminación fuera del contexto de descolonización- pone una vez más en evidencia la existencia de un cierto grado de indeterminación del derecho internacional, que atribuye entonces un rol fundamental a la política en la elección de una posición ${ }^{136}$.

¿Es este rol político condenable? La mayoría de las voces se elevarán ciertamente para defender, a toda costa, el derecho internacional frente a las violaciones flagrantes de sus principios fundamentales y es sin duda el rol que debe cumplir, en primer lugar, el jurista internacionalista. Pero, aunque sea imperativo resistir jurídicamente ante el hecho ilícito, el derecho internacional no puede ignorar la realidad efectiva sobre la cual se sustenta. Por lo mismo, si bien el peso de la política en el funcionamiento del Consejo de Seguridad conlleva debilidades flagrantes en su capacidad de respuesta, no hay que olvidar que la fortaleza del sistema de seguridad colectiva reside, precisamente, en su capacidad de conjugar legitimidad y efectividad -tanto en la adopción de una respuesta como en su aplicación efectiva-, lo que explica que el Consejo sea un órgano político y no judicial. Es la permanencia de este equilibrio, menoscabado por los eventos recientes no solo en Ucrania sino también

133 KoHen (2014).

134 CSNU, S/RES/1973 (2011), párr. 4.

135 KRISCH (2014).

136 Véase, de manera general, Koskenniemi (2005). 
en los otros ejemplos citados, que debe guiar la reflexión de una eventual reforma del Consejo de Seguridad cuando nos aprontamos a celebrar los setenta años de su creación.

En lo que respecta al derecho internacional, sin embargo, la posición no exige tal equilibrio. La respuesta es clara frente al carácter ilícito de las intervenciones ya señaladas -en primer lugar, la anexión de Crimea a la Federación de Rusia- y debe permanecerlo ${ }^{137}$. Si bien, en ciertas situaciones, la primacía de las normas internacionales cede, en cierto punto, ante la realidad fáctica para encontrar una solución política -y no jurídica- al conflicto, solo el rol del derecho internacional explica que esta solución deba ser negociada y no sea únicamente guiada por las relaciones de poder. El derecho internacional conserva así una importancia crucial en los conflictos extremamente politizados, pues, aun cuando la solución definitiva sea política, el derecho impone no solo su negociación, sino también, en cierta medida, las condiciones de su realización.

\section{BIBLIOGRAFÍA CITADA}

Acosta SÁnchez, Miguel Ángel (2014): "La secesión en el derecho internacional: el caso de Crimea", Instituto Español de Estudios Estratégicos (IEEE): 17 p. [fecha consulta: 12 febrero 2015]. Disponible en: <http://www.ieee.es/Galerias/fichero/docs_opinion/2014/DIEEEO142-2014_Secesion_DchoInternacional_Crimea_MA.Acosta.pdf >

Beaucillon, Charlotte (2014): “Crise ukrainienne et mesures restrictives de l'Union européenne: quelle contribution aux sanctions internationales à l'égard de la Russie?”, Journal du droit international, vol. $141 \mathrm{n}^{\circ}$ 3: pp. 787-807.

Bismuth, Régis (2014): "Odyssée dans le conundrum des réactions décentralisées à l'illicite”, Journal du droit international, vol. $141 \mathrm{n}^{\circ}$ 3: pp. 719-731.

Boeglin, Nicolás (2014): “Crimea: Análisis de un referéndum” [fecha consulta: 10 febrero 2015]. Disponible en: <http://revista-amauta.org/2014/03/crimeareferendum/>.

Christakis, Théodore (2006): "L'obligation de non-reconnaissance des situations créées par le recours illicite à la force et d'autres actes enfreignant des règles fondamentales", en: Tomuschat, Christian, Thouvenin, Jean-Marc (edit.), The Fundamental Rules of the International Legal Order: Jus Cogens and Obligations Erga Omnes (Leiden, Martinus Nijhoff) pp. 127-166.

Christakis, Théodore (2007): “La sécession: une question de simple fait?", Working Papers of the European Society for International Law: 15 p. [fecha consulta: 24 febrero 2015]. Disponible en: <http://www.esil-sedi.eu/fichiers/en/Agora_Christakis_855.pdf>.

Christakis, Théodore (2014): “Les conflits de la sécession en Crimée et dans l'est de l'Ukraine et le droit international", Journal du droit international, vol. $141 \mathrm{n}^{\circ}$ 3: pp. 733-764.

DreYFus, Emmanuel (2013): “De l'Union douanière à l'Union eurastiaque. État et perspective d'intégration dans l'espace post-soviétique”, Notes stratégiques du CEI: 49 p. [fecha

\footnotetext{
137 Es preferible que casos como el de Kosovo sean justificados sobre el plano político de la legitimidad a que se creen jurídicamente nuevas excepciones de alcance indefinido a la aplicación de los principios fundamentales del derecho internacional.
} 
consulta: 15 febrero 2015]. Disponible en: <http://www.ceis.eu/fr/actu/note-strategique-de-l-union-douaniere-l-union-eurasiatique-etat-et-perspectives-d-integration $>$.

Eisemann, Pierre Michel (2010): "Lindépendance du Kosovo. Le point de vue du juriste", en: Société française de droit international (edit.), Journée d'études de Paris. Droit international et relations internationales. Divergences et convergences (Paris, Pedone) pp. 107-119.

Fox, Grégory H. (2014), "Ukraine Insta-Symposium: Intervention in the Ukraine by Invitation”, Opinio Juris [fecha consulta: 24 febrero 2015]. Disponible en: <http://opiniojuris.org/2014/03/10/ukraine-insta-symposium-intervention-ukraine-invitation/>.

Goldsmith, Jack (2014): “The Precedential Value of the Kosovo Non-Precedent Precedent for Crimea", Lawfare: Hard National Security Choices [fecha consulta: 10 febrero 2015]. Disponible en: <http://www.lawfareblog.com/2014/03/the-precedential-value-of-thekosovo-non-precedent-precedent-for-crimea/>.

Kohen, Marcelo (2014): "L'Ukraine et le respect du droit international", Le Temps [fecha consulta: 24 febrero 2015]. Disponible en: <http://www.letemps.ch/Page/Uuid/ a02807b0-a9fa-11e3-a7f6-006044306642/LUkraine_et_le_respect_du_droit_international>.

Koskenniemi, Martti (2005): From Apology to Utopia: The Structure of International Legal Argument (Nueva York, Cambridge University Press, 2a ed.).

KrIsCH, Nico (2014): "Crimea and the Limits of International Law", European Society of International Law Talk [fecha consulta: 12 febrero 2015]. Disponible en: <http://www. ejiltalk.org/crimea-and-the-limits-of-international-law/>.

López-Jurado Romero de la Cruz, Carmen (2011): "Kosovo ante la Corte Internacional de Justicia: La opinión consultiva de 22 de julio de 2010”, Revista Electrónica de Estudios Internacionales, $\mathrm{n}^{\circ}$ 21: pp. 1-30.

MartucCI, Francesco (2014): "La réaction multidimensionnelle de l'Union européenne dans la crise ukrainienne", Journal du droit international, vol. $141 \mathrm{n}^{\circ}$ 3: pp. 765-785.

MarXsen, Christian (2014): "Crimea's Declaration of Independence", European Society of International Law Talk [fecha consulta: 10 febrero 2015]. Disponible en: <http://www. ejiltalk.org/crimeas-declaration-of-independence/> .

Mouton, Jean-Denis (1992): "La notion d'État et le droit international public", Droits, n ${ }^{\circ}$ 16: pp. 45-58.

Pellet, Alain (1994): “Quel avenir pour le droit des peuples à disposer d'eux-mêmes?”, en: Rama-Montaldo, Manuel (edit.), El Derecho internacional en un mundo en transformación. Liber Amicorum Jimenez de Arechaga (Montevideo, Fundación de Cultura Universitaria) pp. 255-276.

Pellet, Alain (2013): "What Normativity for the Responsibility to Protect?", en: CHaUmette, Anne-Laure, Thouvenin, Jean-Marc (edit.), The Responsibility to Protect, Ten Years On (Paris, Pedone): pp. 185-191.

Ruiz-FABRI, Hélène (1992): “Genèse et disparition de l'État à l'époque contemporaine”, Annuaire français de droit international, vol. 38: pp. 153-178.

Rodríguez-SantibáNEZ, Iliana (2014): “Ucrania: ecos de la guerra fría”, Tecnológico del Monterrey [fecha consulta: 12 febrero 2015]. Disponible en: <http:/www.itesm.mx/ 
$\mathrm{wps} / \mathrm{wcm} / \mathrm{connect} / \mathrm{snc} /$ portal+informativo/opinion+y+analisis/firmas/dra.+iliana+rodrig uez+santibanez/op(20mar14)ilianarodriguez>.

RuYs, Tom (2008): “The 'Protection of Nationals' Doctrine Revisited”, Journal of Conflict and Security Law, vol. $13 \mathrm{n}^{\circ}$ 2: pp. 233-271.

Salmon, Jean (2001): Dictionnaire de droit international public (Bruselas, Bruylant) xli$1198 \mathrm{pp}$.

Thouvenin, Jean-Marc (2014): “Contra el derecho ucraniano y la ley internacional”, La razón [fecha consulta: 24 febrero 2015]. Disponible en: <http://www.larazon.es/internacional/contra-el-derecho-ucraniano-y-la-ley-internacional-FM5860531\#.Ttt18ZcE1MYoMyJ>.

Vidmar, Jure (2014): "Crimea's Referendum and Secession: Why it Resembles Northern Cyprus More than Kosovo", European Society of International Law Talk [fecha consulta: 10 de febrero 2015]. Disponible en: <http://www.ejiltalk.org/crimeas-referendum-andsecession-why-it-resembles-northern-cyprus-more-than-kosovo/>.

WaLdOCK, Humphrey (1952): “The Regulation of the Use of Force by Individual States in International Law", Collected Courses of the Hague Academy of International Law, vol. 81: pp. 451-517.

Wilson, Gary (2014): The United Nations and Collective Security (Nueva York, Routledge) xvi-247 pp.

Wisehart, Daniel (2014): "The Crisis in Ukraine and the Prohibition of the Use of Force: A Legal Basis for Russia's Intervention?”, European Society of International Law Talk [fecha consulta: 10 febrero 2015]. Disponible en: <http://www.ejiltalk.org/the-crisis-inukraine-and-the-prohibition-of-the-use-of-force-a-legal-basis-for-russias-intervention/>.

\section{NORMAS CITADAS}

Carta de las Naciones Unidas, 19 junio 1945 (en vigor 24 octubre 1945).

Estatuto de Roma, 17 julio 1998 (en vigor 1 julio 2002).

Tratado de Funcionamiento de la Unión Europea, 13 diciembre 2007 (en vigor 1 diciembre 2009).

Federación de Rusia, Ley del 21 marzo de 2014, Federal Constitutional Law On Admitting to the Russian Federation the Republic of Crimea and Establishing within the Russian Federation the New Constituent Entities of the Republic of Crimea and the City of Federal Importance Sevastopol.

Federación de Rusia, Ley del 21 marzo de 2014, Federal Law On Ratifying the Agreement between the Russian Federation and the Republic of Crimea on Admitting to the Russian Federation the Republic of Crimea and Establishing within the Russian Federation New Constituent Entities.

Ucrania, Ley No 1207-VII, 15 abril 2014, Law On Securing the Rights and Freedoms of Citizens and the Legal Regime on the Temporarily Occupied Territory of Ukraine.

Ucrania, Ley No 1237-VII, 6 mayo 2014 (modifica Ley No. 1207-VII). 


\section{JURISPRUDENCIA CITADA}

CIJ, Conséquences juridiques pour les États de la présence continue de l'Afrique du Sud en Namibie (Sud-Ouest africain) nonobstant la résolution 276 (1970) du Conseil de sécurité (1976): opinión consultativa, 21 junio 1971.

CIJ, Activités militaires et paramilitaires au Nicaragua et contre celui-ci (Nicaragua c. ÉtatsUnis d'Amérique), fond (1986): sentencia, 27 junio 1986.

CIJ, Timor oriental (Portugal c. Australie) (1995): sentencia, 30 junio 1995.

CIJ, Plates-formes pétrolières (République Islamique d'Iran c. États-Unis d'Amérique) (2003): sentencia, 6 noviembre 2003.

CIJ, Conformité au droit international de la déclaration unilatérale d'indépendance relative au Kosovo (2010): opinión consultativa, 22 julio 2010.

Corte Permanente de Justicia Internacional, Affaire relative à certaines intérêts allemands en Haute-Silésie Polonaise (fond) (1926): sentencia, 25 mayo 1926.

Tribunal Constitucional de Ucrania (2014), 14 marzo 2014, No. 02-rp/2014, Decision in the case on the constitutional petition of the Acting President of Ukraine, the Chairman of the Verkhovna Rada of Ukraine, the Ukrainian Parliament Commissioner for Human Rights concerning the compliance with the Constitution of Ukraine (constitutionality) of the Resolution of the Verkhovna Rada of the Autonomous Republic Crimea "On holding the allCrimean referendum" (the case on the all-Crimean referendum in the Autonomous Republic of Crimea).

Tribunal Constitucional de Ucrania (2014), 20 marzo 2014, No. 03-rp/2014, Decision in the case upon the constitutional petition of the Acting President of Ukraine, Chairman of the Verkhovna Rada of Ukraine concerning conformity to the Constitution of Ukraine (constitutionality) of the Resolution of the Verkhovna Rada of the Autonomous Republic of Crimea "On the Declaration of Independence of the Autonomous Republic of Crimea and the City of Sevastopol".

Tribunal Constitucional de Rusia (2014), 19 marzo 2014, No. 6- /2014, Judgment on the case concerning the review of the constitutionality of the International Treaty Between the Russian Federation and the Republic of Crimea on Admission of the Republic of Crimea into the Russian Federation and Creation of Nez Subjects in the Composition of the Russian Federation, pending its entry into force, in connection with the request of the President of the Russian Federation.

\section{RESOLUCIONES Y DOCUMENTOS DE TRABAJO DE ORGANIZACIONES INTERNACIONALES CITADOS}

\section{Organización de las Naciones Unidas}

AGNU, "Declaración sobre la concesión de la independencia a los países y pueblos coloniales", A/RES/1514 (XV), 14 diciembre 1960.

AGNU, "Principios que deben servir de guía a los Estados Miembros para determinar si existe o no la obligación de transmitir la información que se pide en el inciso e del artículo 73 de la Carta”, A/RES/1541 (XV), 15 diciembre 1960. 
AGNU, "Cuestión de una Repartición en el Consejo de Seguridad y en el Consejo Económico y Social”, A/RES/1991 (XVIII), 17 diciembre 1963.

AGNU, "Declaración relativa a los principios de derecho internacional referentes a las relaciones de amistad y a la cooperación entre los Estados de conformidad con la Carta de las Naciones Unidas", A/RES/2625 (XXV), 24 octubre 1970.

AGNU, “Definición de la agresión”, A/RES/3314 (XXIX), 14 diciembre 1974.

AGNU, "Responsabilidad del Estado por hechos internacionalmente ilícitos", A/ RES/56/83, 12 diciembre 2001.

AGNU, "Documento Final de la Cumbre Mundial 2005", A/RES/60/1, 16 septiembre 2005.

AGNU, "Admisión de la República de Sudán del Sur como Miembro de las Naciones Unidas", A/RES/65/308, 14 julio 2011.

AGNU, "Integridad territorial de Ucrania”, A/RES/68/262, 27 marzo 2014.

CSNU, S/RES/216 (1965), 12 noviembre 1965.

CSNU, S/RES/541 (1983), 18 noviembre 1983.

CSNU, S/RES/662 (1990), 9 agosto 1990.

CSNU, S/RES/678 (1990), 29 noviembre 1990.

CSNU, S/RES/687 (1991), 3 abril 1991.

CSNU, S/RES/787 (1992), 16 noviembre 1992.

CSNU, S/RES/1973 (2011), 17 marzo 2011.

CSNU, S/PV.7124, 1 marzo 2014.

CSNU, S/PV.7125, 3 marzo 2014.

CSNU, S/2014/189, 15 marzo 2014.

CSNU, S/PV.7157, 16 abril 2014.

CSNU, S/RES/2166 (2014), 21 julio 2014.

CSNU, S/RES/2202 (2015), 17 febrero 2015.

ONU (1957): "Report of the Special Committee on the Problem of Hungary. General Assembly Official Records: Eleventh Session Supplement No. 18 (A/3592)", 268 p., [fecha consulta: 24 febrero 2015]. Disponible en: <http://mek.oszk. hu/01200/01274/01274.pdf >.

\section{UNIÓN EUROPEA}

Consejo de LA Unión Europea, Decisión 2014/119/PESC relativa a medidas restrictivas dirigidas contra determinadas personas, entidades y organismos habida cuenta de la situación en Ucrania, 5 marzo 2014, Diario Oficial de la Unión Europea, L 66/26.

Consejo de la Unión Europea, Decisión 2014/145/PESC relativa a medidas restrictivas respecto de acciones que menoscaban o amenazan la integridad territorial, la soberanía y la independencia de Ucrania, 17 marzo 2014. 